\title{
Electrical control strategy for an ocean energy conversion system
}

\author{
Muhammad Noman, Guojie Li $i^{*}$, Keyou Wang and Bei Han
}

\begin{abstract}
Globally abundant wave energy for power generation attracts ever increasing attention. Because of non-linear dynamics and potential uncertainties in ocean energy conversion systems, generation productivity needs to be increased by applying robust control algorithms. This paper focuses on control strategies for a small ocean energy conversion system based on a direct driven permanent magnet synchronous generator (PMSG). It evaluates the performance of two kinds of control strategies, i.e., traditional field-oriented control (FOC) and robust adaptive control. The proposed adaptive control successfully achieves maximum velocity and stable power production, with reduced speed tracking error and system response time. The adaptive control also guarantees global system stability and its superiority over FOC by using a non-linear back-stepping control technique offering a better optimization solution. The robustness of the ocean energy conversion system is further enhanced by investigating the Lyapunov method and the use of a DC-DC boost converter. To overcome system complexity, turbine-generator based power take-off (PTO) is considered. A Matlab/Simulink study verifies the advantages of a non-linear control strategy for an Oscillating Water Column (OWC) based power generation system.
\end{abstract}

Keywords: OWC, Ocean wave power generation, Robust adaptive control, FOC, PMSG, Wells turbine

\section{Introduction}

Earth's natural resources are in tight supply in satisfying the world's increasing energy needs. Using renewable energy sources to enhance energy production is a common agenda of the industrialized world. The primary sources of ocean energy are waves, currents, and ocean thermal energy. It is estimated that ocean energy can potentially provide $10 \%$ of Europe's current electricity consumption by 2050 [1]. Based on theoretical analysis, ocean wave energy across the globe is about 2 TW [2, 3], while its availability and energy density make it a better alternative to wind energy. However, power generation from ocean waves still has a long way to go before reaching full-scale development as the available advanced devices and their control are expensive. Ocean wave power production can be maximized by developing efficient,

\footnotetext{
* Correspondence: liguojie@sjtu.edu.cn

Key Laboratory of Control of Power Transmission and Conversion (SJTU),

Ministry of Education, Shanghai, China
}

robust and cost-effective technologies so as to raise ocean wave energy from a research domain to the mainstream of clean power generation. Since the drawbacks of known technologies can significantly increase the cost of power production, it is necessary to provide optimized and smart solutions. As the net cost of the energy produced by ocean renewables is higher than conventional energy generation, power production based on wave energy has had limited commercial exploitation [4]. The net energy cost can be given as:

$$
\text { Energy cost }=\frac{\text { Capital cost }+\mathrm{PV}(\mathrm{OM} \text { cost })}{\mathrm{PV}(\text { Produced energy })}
$$

In (1), all three components are critical driving terms and are using present value (PV) techniques [5]. The Carbon Trust has stipulated that significant gains can be obtained in the energy production domain [6]. Previously, ocean wave energy developers have focused on wave energy converter (WEC) control, a PTO mechanism, and component improvement. However, high-end

\section{Springer Open}

(c) The Author(s). 2021 Open Access This article is licensed under a Creative Commons Attribution 4.0 International License, which permits use, sharing, adaptation, distribution and reproduction in any medium or format, as long as you give appropriate credit to the original author(s) and the source, provide a link to the Creative Commons licence, and indicate if changes were made. The images or other third party material in this article are included in the article's Creative Commons licence, unless indicated otherwise in a credit line to the material. If material is not included in the article's Creative Commons licence and your intended use is not permitted by statutory regulation or exceeds the permitted use, you will need to obtain permission directly from the copyright holder. To view a copy of this licence, visit http://creativecommons.org/licenses/by/4.0/. 
power production based on ocean waves is under development and has not yet reached full potential and robust electrical control needs attention for further improvement. The development of new electrical control laws is vital for the wave power generation system to lead the power generation sector towards a better operating and safe environment. A comprehensive description and review for the employment of developed ocean wave energy technologies, including the fundamental principles of absorbing wave energy and controls for maximum power output, is provided in [7-10].

Renewable energy sources are complex systems that require new control strategies to guarantee optimum energy production and better efficiency [11]. However, ocean wave power production and its control are complex domains, and therefore developing an efficient control design plays an essential role in improving overall system efficiency, performance, and cost. Among the wide range of developed technologies, only a few concepts can convert wave energy into usable energy [12, 13]. In [14], the presented OWC characteristic curve tracking and generator control performance promote the usage of OWC-based power generation systems.

Researchers are trying to introduce novel control designs that can reduce the level of machine non-linearity in the wave power generation systems. Thus it is crucial to design an appropriate machine-side electrical control strategy to ensure better performance and stable power generation from OWC-based power generation plants by implementing speed tracking control strategies.

In this paper, the proposed electrical control regulates the Wells turbine speed and extracts maximum power from the system by applying an appropriate optimization solution. Moreover, the applied optimization for the OWC-based Wells turbine also faces a stalling phenomenon, as can be seen in Section 5. This work provides an optimal solution for the PMSG-based ocean wave power generation system by ensuring adequate PMSG speed tracking response. The proposed adaptive control algorithm works for the machine side converter (MSC) of the PMSG-based power generation systems, and this is connected back-to-back to its grid side inverter through a DC capacitor [15-17].

We also analyze the effect of implementing backstepping control, specifically for the PMSG-based ocean wave energy conversion system. The advantages of PMSG, including better low-speed performance and easy control, make it a better choice. The PMSG design can deliver better performance under constant and variable speed environments while maintaining the optimal flow coefficient values. This results in high Wells turbine efficiency.

The PMSG behaves like a non-linear multivariable dynamic system. Therefore to maximize the PMSG dynamic performance, vector control theory can be applied, where the variables of power generators are converted to orthogonal components [18]. In the presence of non-linearity, rotor speed accuracy and current control are difficult tasks [19]. When the PMSG operates in a field weakening region, the power system non-linearity control becomes more severe so decoupled control is applied.

\subsection{Problem statement}

Existing power generation systems are largely controlled by traditional control schemes using proportionalintegral (PI) controllers. Our goal is to assess a new control algorithm for a PMSG-based ocean energy conversion system. A PI controller behaves like a linear regulator. This makes it sensitive to power system parametric variations and is not an optimal way of providing a solution for electromechanical systems. Several control strategies have been developed to deal with the uncertainties and disturbances of the concerned parameters in different respects. In [20], the PI strategy and backstepping control are designed for a wind energy conversion system. It presents simple and robust control of the PMSG at its rated velocity. In [21], Wells turbine realtime behavior is presented. This achieves its efficiency using a PI controller. In the two studies, different approaches are used.

The presence of system uncertainties is a challenge for practical implementation. Therefore to ensure improved system performance under non-linear dynamic situations and potential uncertainties, it is preferable to use a robust control design. To achieve this, the feasibility of the applied adaptive control strategy is carefully verified and compared with the FOC control strategy.

The goal is to improve and replace the conventional electrical control technique by introducing backstepping control for the PMSG-based WEC, and to guarantee the global stability of the OWC device-based ocean energy conversion system. An applied adaptive control algorithm with non-linear nature and Lyapunov stability technique can provide desired results without considering the typical analytical models in a complete power system. The presented robust control algorithm does not rely on machine parameters required for the FOC control. Hence, parametric identification is not required for its smooth regulation. The main objectives of this paper are as follows:

- To analyze the advantages of using a robust adaptive control strategy by minimizing the drawbacks of FOC.

- To ensure power system optimization using an efficient non-linear electrical control strategy. 


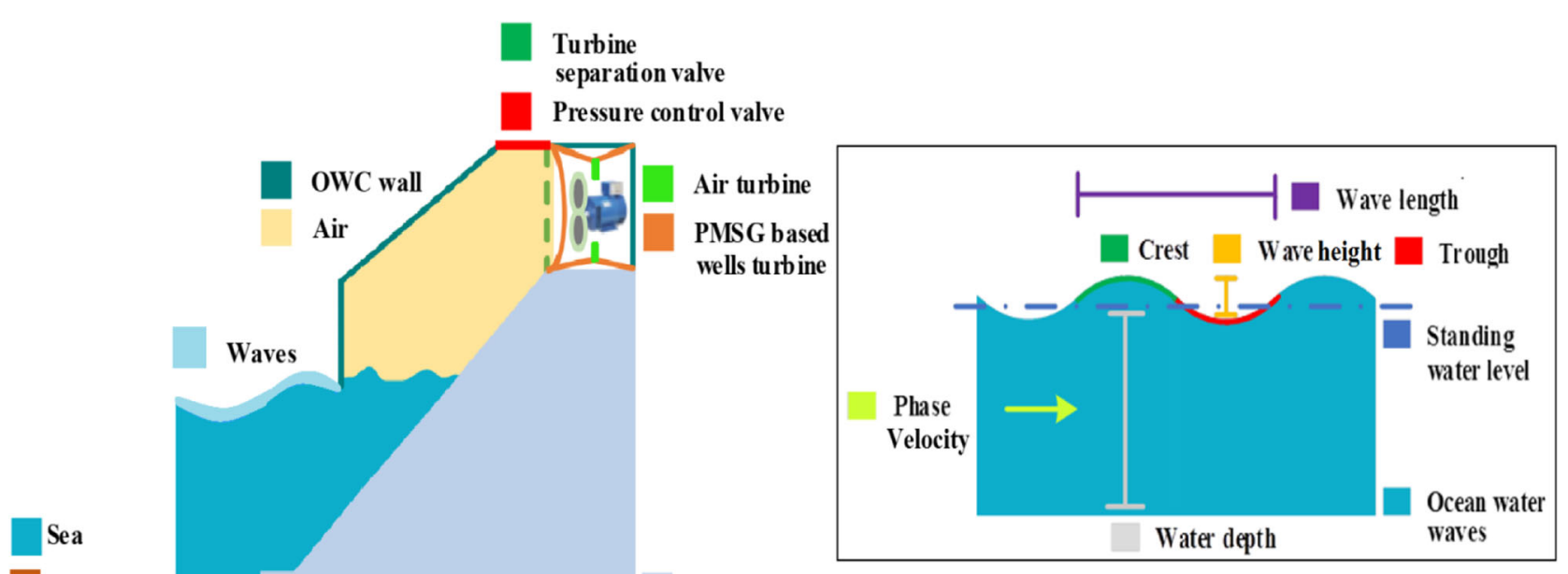

Ocean floor

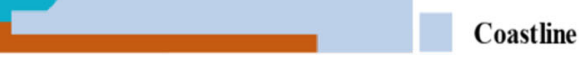

Fig. 1 Representation of ocean wave converter. a) OWC chamber layout. b) Ocean wave concept

- To enhance system performance by implementing a back-stepping control strategy based on Lyapunov stability.

- To reduce system harmonics, torque, and speed errors, providing stable power generation from the PMSG-based ocean energy conversion system.

- To deliver constant and balanced three-phase power supply at the load side.

\subsection{Recent studies on control strategies for renewable energy sources}

Electrical control of wind and ocean renewable energy systems can be treated similarly in some respects. The efficiency and behavior of renewable energy resources highly depend on the applied control strategies. To control the PMSG-based wind energy system, the maximum power point tracking (MPPT) and the pitch control strategies are generally used [22]. Incremental conductance algorithm-based MPPT control strategy, intelligent airflow control, input-output linearization control, sliding mode control (SMC) for a doubly-fed induction generator (DFIG)-based power generation system, SMC for cage asynchronous motor, fuzzy logic control, adaptive back-stepping control $(\mathrm{ABC})$, and several other control strategies have been reported
[23-36]. A sensorless control strategy of small wind energy conversion system (WECS) is presented in [33]. The maximum wind energy has been generated by analyzing the dynamic feedback-feedforward (FFC) controller with extended Kalman filter (EKF) [34]. Two types of control strategies for OWC are also presented in $[29,36-38]$, i.e., airflow control and rotational speed control. Because of fluctuations in wave frequency, wind speed, or weather conditions, overall system efficiency reduces [39]. Thus in [39, 40], OWC efficiency issues are addressed.

The Wells turbine efficiency also depends on flow rate and oscillation. Flow oscillation in the Wells turbine decreases efficiency while unnecessary flow rate in the OWC chamber can be controlled using various air valve control methods proposed in [41-43]. They are designed to match the available wave level and airflow control through the turbine, preventing or reducing the aerodynamic blade losses at the turbine rotor blades. Under real-time operation, the factors mentioned above can lower the combined efficiency to below the theoretical efficiency (70-80\%) [44]. The power capturing efficiency for a single cylindrical OWC can be enhanced by implementing a finite element model by understanding the complex wave-structure interactions in the arrays of fixed OWC devices [35]. In [36], variable frequency

Table 1 Recently developed control strategies for the OWC device

\begin{tabular}{|c|c|c|}
\hline Control strategies for OWC & Available topologies & Summary \\
\hline Airflow control & $\begin{array}{l}\text { i. Parallel valve set up with a turbine } \\
\text { ii. Series mounted valve with a turbine }\end{array}$ & $\begin{array}{l}\text { Series topology is better than parallel topology. It controls unnecessary } \\
\text { stalling behavior, which results in high output power. }\end{array}$ \\
\hline Speed control & $\begin{array}{l}\text { i. Stator-based velocity/hertz control } \\
\text { ii. Rotor-based velocity/hertz } \\
\text { iii. Uncontrolled structure } \\
\text { iv. Constant torque control scheme } \\
\text { v. Regular and variable speed control } \\
\text { vi. Speed control (within oscillation range) }\end{array}$ & $\begin{array}{l}\text { In comparison with other topologies, stator control is a better optimal } \\
\text { solution, and available numerical simulations in (vi) show that the } \\
\text { speed control within acceptable oscillation range is a better optimal } \\
\text { solution. Variable speed control is based on the feedback control } \\
\text { strategy. }\end{array}$ \\
\hline
\end{tabular}


Table 2 Various control methods for renewable energy systems

\begin{tabular}{ll}
\hline Available control methods & Authors \\
\hline $\begin{array}{l}\text { Air turbine control, flow control, generator selection, speed control } \\
\text { for OWC }\end{array}$ & Setoguchi, T., \& Takao, M., (2006) [37]; Justino, P., A., P., \& de O., Falca O, \\
Traditional control strategies and PI control scheme (OWC), fuzzy & A., F., (May 1, 1999) [40]; O'Sullivan, D., L., \& Lewis, A., W., (2011) [71] \\
logic control and optimal and non-linear speed control (OWC) & Amundarain, M., et al. (2010) [10]; Mishra, S., K., \& Aradhna, Patel, (2017) \\
Adaptive second-order SMC, sensorless control, PMSG non-linear & [21]; Mishra, S., K., et al. (2016) [16, 30] \\
$\begin{array}{l}\text { control, optimized power tracking control, adaptive SMC (OWC), } \\
\text { frequency control, feed-forward and robust control (OWC), DFIG }\end{array}$ & Matraji, et al. (2018) [58]; Shototbani, et al. (2019) [62]; Fantino, et al. \\
$\begin{array}{l}\text { Luenberger-based observer (OWC), predictive control, close-to- } \\
\text { optimal latching control (OWC) }\end{array}$ & (2016) [63]; Mishra, S., K., et al. (2018) [72]; Barambones, O., et al. (2018) \\
\hline
\end{tabular}

control of an OWC is implemented using the cubic relationship between the rotor frequency and instantaneous power.

WEC performance can also be improved by implementing efficient rotational speed control [44-47]. Recently, three methods have been developed for turbine rotational speed control under a required flow range: (a) power estimation-based constant torque control [46], (b) speed control using a linear derivative function, and (c) control under sustainable oscillation [47]. In these methods, the uncertainty can limit the system response time and energy production. Hence, the objective of controlling the rotational speed is to regulate the generated power. This is achieved by controlling torque through the power conditioning equipment.

Control strategies affect not only energy engagement but also system robustness and maintenance. In [48], control under suitable oscillations is considered an optimal solution for a better electric power output control in the OWC device, and consists of a programmable logic controller (PLC). In $[49,50]$, a turbine-generator systembased torque control algorithm is designed to control the turbine rotational speed for the inverter drive attached to the generators. It consists of a switchboard feeding its corresponding generator system and connecting the power plant to the grid side through a transformer. Connected generators are controlled by the supervisory controller through the inverter drive [51]. A control system inland installed marine power energy transmitter (LIMPET) adjusts the rotor speed by optimizing its rotational speed and the fluid flow velocity [52].

In addition, three types of rotational speed control strategies are available [53]: (a) constant torque control, (b) constant power control, and (c) constant speed control. They regulate the mean rotational speed to establish the optimal speed by focusing on the generator torque demand. In [54], simulations for speed control topologies that are related to the Wells turbine are compared, i.e.: (i) uncontrolled, (ii) stator-based velocity/frequency control [55], and (iii) rotor-based velocity/frequency control. As uncontrolled variations in power can harm the grid, it is suggested that the optimal topology should be implemented for the Wells turbine stator.
Robust electrical control strategies have rarely been studied for OWC devices. For this, understanding of various control topologies is necessary. To design a back-stepping control, the selection of recursive and suitable functions can be made possible by using state variables, which act as pseudo control inputs for lower dimension subsystems. Each back-stepping proceeding directs towards a new pseudo control design. Adaptive control can provide high performance against the dynamics, and is insensitive to parametric variation [56].

In this research, other aims of applying adaptive control for the WEC are to decrease hardware complexity and drive size. Back-stepping control can make a reasonable improvement in the transient mode. In [57], the effectiveness of using back-stepping control is verified. It can provide better system performance in the transient mode with a controlled overshoot. In [58], a backstepping control design using second-order PMSG-based SMC is presented with a designed wind emulator using a Super Twisting (ST) algorithm for wind energy power generation conversion. Clicking issues are also reduced by introducing an adaptive super twisting (AST) algorithm, while the adaptive control efficiency is verified by experiment.

In [59], the speed and position control for a permanent magnet synchronous motor are evaluated using a sensorless high-order SMC strategy, providing high-end control performance. In [60-62], robust performance of the system while extracting maximum available power is presented. In [63], a Luenberger non-linear observer is presented to provide speed estimation of a PMSG without mechanical sensors, and the effectiveness of using a non-linear observer-based control strategy is proved.

In [64], a comparison of PMSG-based SMC with classical PI controllers is presented. The results presented verify the improvement achieved by applying non-linear SMC control for static and dynamic modes in maximizing the power extraction under variable conditions. In [65], a field-programmable gate array (FPGA)-based robust adaptive control solution is used for a DFIG-based wind energy system, while the results verify the reliability of the proposed non-linear control under functional and variable wind conditions. In [66], a robust sensorless 
control design is proposed for maximum power efficiency without feedback by considering the rotor position, speed, and wind velocity.

From this subsection, it can be concluded that robust and efficient electrical control studies for a PMSGbased WEC have not received sufficient attention. Therefore, to achieve robust performance, an efficient adaptive control strategy is designed in this paper. For this purpose, the OWC chamber is selected to absorb the kinetic energy from incident sea waves. It consists of a land-backed water column chamber which creates a significant pressure drop [3]. The most suitable power capturing OWC device type can be selected from the available designs and prototypes operating world-wide [67-69].

This paper is organized as follows. Section 2 introduces the complete modelling process of the OWC device setup. In Section 3, major control strategies, along with the applied adaptive controller design, are presented. Section 4 covers an energy storage scheme for the DC-link while Section 5 deals with the results from the simulation and discusses the feasibility of this research work. Finally, Section 6 draws the conclusion by analyzing the critical outcomes of this research.

\section{Ocean energy conversion system modelling}

\subsection{Selection of ocean wave device}

Here the modelled OWC device consists of an open front side structure to let the waves enter the ocean wave device (OWD) and the rear end is stretched down to the seabed, as shown in Fig. 1. In the simulation, the pressure drop is used as input for the Wells turbine. OWDs are categorized into two major groups of active and passive devices [70]. The arriving waves cause the water level to oscillate which leads to air compression inside the chamber. The air flows inward and outward through a turbine duct to rotate the Wells turbine. This composite event involves energy transfer between the approaching waves and the pneumatic, aerodynamic, hydrodynamic, and electrical PTO attributes of the OWD. In Fig. 1, if the chamber pressure and the atmosphere become too high, the bypass valve can be used to allow the air to move. The turbine airflow is kept under control by introducing a shut-off valve limiting the airflow through the Wells turbine.

\subsubsection{Modelling of the oscillating water column}

The OWC type ocean wave device is modelled in the time domain in a Matlab/Simulink environment. The available incident wave power [W] in the OWC ocean wave device over a wave cycle can be expressed as [79]:

$$
P_{i}=\left(d p_{t u r b}+\frac{\rho_{a} \cdot v_{x}^{2}}{2}\right) A_{t u r b} v_{x}
$$

where $d P_{\text {turb }}$ represents the turbine duct differential pressure $[\mathrm{Pa}], \rho_{a}$ is the density of air $\left[\mathrm{kg} \cdot \mathrm{m}^{-3}\right], A_{\text {turb }}$ represents the cross-sectional area of the turbine duct $\left[\mathrm{m}^{2}\right]$, and $v_{x}$ is the speed of airflow $\left[\mathrm{m} \cdot \mathrm{s}^{-1}\right]$.

In order to generate and implement accurate ocean water waves in Matlab/Simulink, many techniques for regular waves have been proposed in multiple applications of wave-particle kinematics corresponding to the varying complexity of ocean waves [80, 81]. Several water wave theories have been presented to examine the characteristics of ocean water waves [82], including wave theory, Stokes second-order waves theory, high order theories, finite-amplitude wave theory, stream, solitary, and cnoidal wave theories. The velocity of an airflow crossing through the turbine duct can be implemented by studying Airy wave theory. A wide range of wave climate spectra, OWC device dimensions, parameters, and prototypes are reported [83]. The velocity of airflow at the passage of the turbine can be expressed as:

$$
v_{x}(t)=\left(\frac{8 a c W}{\pi D^{2}}\right)\left(\sin \frac{\pi L}{c T} \cos \frac{2 \pi}{T}(t)\right)
$$

where $T$ is wave period [sec], $L$ is the length [m], and $W$ is the width of the OWC chamber. $a$ is the ocean wave amplitude $[\mathrm{m}], D$ is the Wells turbine duct diameter, and $c$ is the regular propagation speed.

\subsubsection{Modelling of Wells turbine}

OWCs are categorized based on their shape, PTO units, and location requirements. The Wells turbine was first developed by Professor Alan Wells of Queen's University of Belfast in the late 1970s [84]. Note that the compressed air goes through a bi-directional turbine. Varieties of equations shown in (4) are used for modelling purposes $[16,85]$.

$$
\left\{\begin{array}{l}
d p_{\text {turb }}=\left(\frac{C_{a} k_{\text {turb }}}{A_{\text {turb }}}\right)\left[v_{x}^{2}+\left(R_{\text {turb }} \omega_{\text {turb }}\right)^{2}\right] \\
k_{\text {turb }}=\left(\frac{n_{t}}{2}\right)\left(\rho_{a} b_{t} l_{t}\right) \\
C_{a}=\frac{\left(A_{\text {turb }} d p_{\text {turb }}\right)}{\left[k_{\text {turb }}\left\{v_{x}^{2}+\left(R_{\text {turb }}\left(\omega_{\text {turb }}\right)^{2}\right\}\right]\right.} \\
C_{t}=\frac{T_{\text {turb }}}{\left[k_{\text {turb }} R_{\text {turb }}\left\{v_{x}^{2}+\left(R_{\text {turb }} \omega_{\text {turb }}\right)^{2}\right\}\right]} \\
T_{\text {turb }}=\left(C_{t} k_{\text {turb }} R_{\text {turb }}\right)\left[v_{x}^{2}+\left(R_{\text {turb }} \omega_{\text {turb }}\right)^{2}\right] \\
T_{\text {turb }}=\frac{d p_{\text {turb }} A_{\text {turb }} C_{t} R_{\text {turb }}}{C_{a}} \\
\phi=\frac{v_{x}}{R_{\text {turb }} \omega_{\text {turb }}} \\
\omega_{\text {turb }}^{*}=\omega_{r}^{*}=A_{1}\left(\overline{\phi_{t_{\text {avg }}}}\right) \\
Q=A_{\text {turb }} v_{x} \\
P_{\text {turb }}=T_{\text {turb }} \omega_{\text {turb }} \\
\eta_{\text {turb }}=\frac{P_{\text {turb }}}{P_{i}}=\frac{C_{t}}{C_{a} \phi}=\frac{T_{\text {turb }} \omega_{\text {turb }}}{d p_{\text {turb }} Q}
\end{array}\right.
$$


where $R_{\text {turb }}$ is the Wells turbine mean radius $[\mathrm{m}], l_{t}$ is the length of blade chord [m], $n_{t}$ is the number of turbine blades, $k_{\text {turb }}$ is a constant $\left[\mathrm{kg} . \mathrm{m}^{-1}\right]$, and $\phi$ is the turbine flow coefficient. $\omega_{\text {turb }}$ is the ocean wave turbine angular speed [rad. $\mathrm{s}^{-1}$ ] and $T_{\text {turb }}$ is the Wells turbine torque. $A_{1}$ and $A_{2}$ represent the constants obtained from mean optimum speed and pneumatic power of generator, respectively. $\Phi_{\text {tavg }}$ is the sorted OWC pressure under average time span, $b_{t}$ is the height of turbine blade [m], and $C_{a}$ and $C_{t}$ are the turbine power and torque coefficients, respectively. $P_{\text {turb }}$ is the turbine power [W], $Q$ is the flow rate $\left[\mathrm{m}^{3} . \mathrm{s}^{-1}\right]$, and $\eta_{\text {turb }}$ is the turbine efficiency.

The OWC device converts wave energy by availing wave elevation to compress or decompress the available air in a chamber. The exhaling and inhaling air travels to and from space through a self-rectifying turbine, which drives an electric power generator. This characteristic of the Wells turbine is due to its specially designed symmetric blade figure, as shown in Fig. 2. It operates on aerofoil theory and a lift over the aerofoil generates the Wells turbine rotation by producing an excellent tangential torque force outline [86].

\subsubsection{Modelling of permanent magnet synchronous generator}

In this study, the PMSG speed is maintained at a constant level. The optimum way of modelling threephase PMSG is achieved by applying the Park transformation, in which the physical three-phase part is converted into an orthogonal two-axes $d$ - $q$ reference frame. The rotor position is set at $90^{\circ}$ behind phase Aaxis, while at $\theta_{r}=0$, the $d$-axis is in adjustment with the position of the permanent magnet rotor. Since the rotor rotates with the $d-q$ frame of reference at the synchronous angular speed, the PMSG voltage equations under the $d-q$ reference frame and stator flux can be expressed as [87]:

$$
\begin{gathered}
\left\{\begin{array}{l}
v_{d s}=i_{d s} R_{s}+\frac{d \lambda_{d s}}{d t}-\omega_{e} \lambda_{q s} \\
v_{q s}=i_{q s} R_{s}+\frac{d \lambda_{q s}}{d t}+\omega_{e} \lambda_{d s}
\end{array}\right. \\
\begin{cases}\lambda_{d s} & =L_{d} i_{d s}+\lambda_{p m} \\
\lambda_{q s} & =L_{q} i_{q s}\end{cases}
\end{gathered}
$$

where $R_{s}$ is the stator winding resistance, and $L_{d}$ and $L_{q}$ are the inductances in the $d-q$ axes. $\omega_{e}$ is the synchronous electrical speed frequency and $\lambda_{p m}$ is the rotor magnet flux linkage from the permanent magnet. Also, $T_{e}$ is calculated as:

$$
\left\{\begin{array}{l}
T_{e}=\frac{3 P}{2}\left[\lambda_{p m} i_{q s}+\left(L_{d}-L_{q}\right) i_{d s} i_{q s}\right] \\
T_{e}=\frac{3 P}{2}\left(\lambda_{p m} i_{q s}\right)
\end{array}\right.
$$

where $P$ is the number of poles. For a surface-mounted PMSG, $L_{d}=L_{q}$ so the equations for $T_{e}$ can be rewritten as:

$$
\left\{\begin{array}{c}
\frac{d \omega_{r}}{d t}=\frac{T_{\text {turb }}-T_{e}-\omega_{r} K_{D}}{J} \\
\frac{d \theta_{r}}{d t}=\omega_{e} \\
\frac{d \theta_{r}}{d t}=\omega_{r} P
\end{array}\right.
$$

where $\omega_{r}$ is the mechanical rotor speed of the PMSG $\left[\mathrm{rad} . \mathrm{s}^{-1}\right]$ and $K_{D}$ is the damping coefficient [Nm.s.rad $\left.{ }^{-1}\right]$. In this modelling, the viscous friction coefficient and the total inertia are known, while in the real world, the designed and measured values may vary owing to manufacturing process variations and differences according to time.

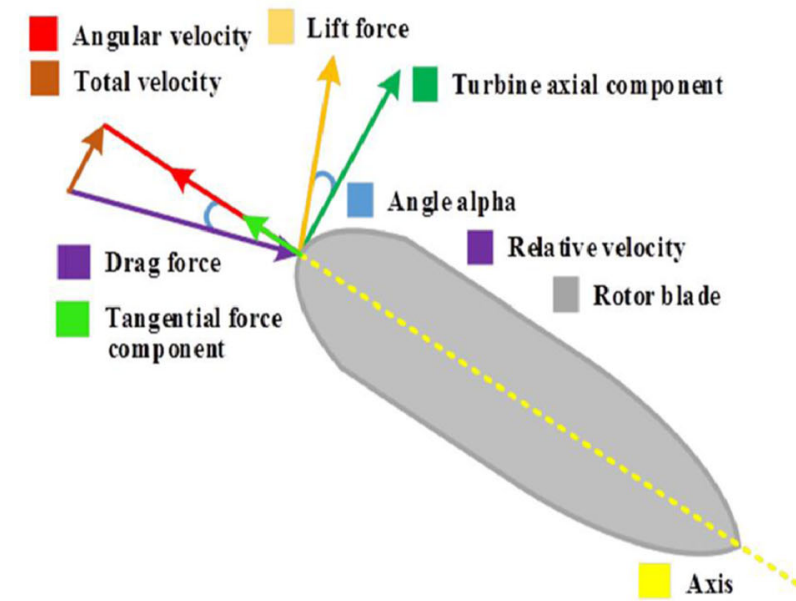

Fig. 2 Wells turbine concept and illustration of acting components on a turbine rotor blade. a Schematic representation of the Wells turbine. $\mathbf{b}$ Representation of aerodynamic forces 


$$
\left\{\begin{array}{l}
\frac{d i_{d s}}{d t}=\frac{1}{L_{d}}\left(-R_{s} i_{d s}+\omega_{e} i_{q s} L_{q}+v_{d s}\right) \\
\frac{d i_{q s}}{d t}=\frac{1}{L_{q}}\left(-R_{s} i_{q s}-\omega_{e} i_{d s} L_{d}-\omega_{e} \lambda_{p m}+v_{q s}\right) \\
\frac{d i_{q s}}{d t}=\frac{1}{L_{q}}\left(-R_{s} i_{q s}-\omega_{e} i_{d s} L_{d}+v_{q s}\right)
\end{array}\right.
$$

\section{Applied control strategies to the ocean energy conversion system}

\subsection{Machine side converter control}

This section designs and simulates the FOC and robust adaptive control strategies. For the nominal PMSGbased Wells turbine, the measured angular and rotor mechanical speed is acquired for the MPPT scheme. The applied MSC control strategy controls flux and torque separately, and this is achieved by the FOC control strategy [88].

\subsubsection{Space vector pulse width modulation technique}

In order to enhance the usage of the three-leg, back-toback power converters, an efficient space vector pulse width modulation (SVPWM) technique is applied [89].

The space vector concept is shown in Fig. 3. The reason for using this technique is to refine the system behavior by minimizing the potential harmonic contents, switching losses, and to achieve maximum DC bus voltage utilization.

\subsubsection{Implementation of maximum power point tracking scheme}

The selected OWC device delivers an optimized power over a specific speed range. The obtained $T_{\text {turb }}$ as expressed in (4) determines the applied force on the generator shaft [79]. The optimum value changes

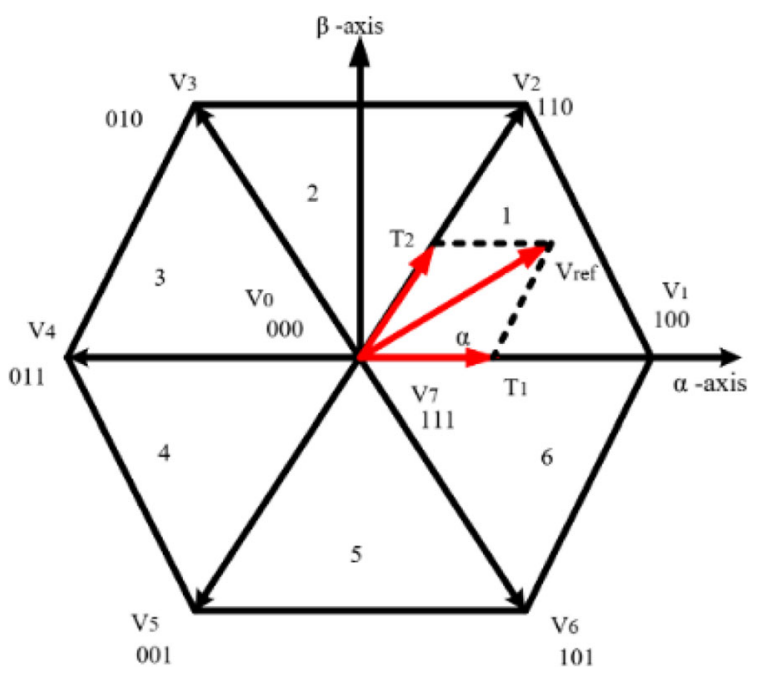

Fig. 3 Illustration of space vector concept according to the incident wave. Therefore, the torque and flow coefficient are linked to the Wells turbine rotational speed. Thus the pressure drop and rotor resistance are calculated so that the flow coefficient remains lower than 0.3. Hence, $\phi_{\max }$ can be expressed as:

$$
0.27 \leq \phi_{\max } \leq 0.3
$$

The purpose of the applied MPPT scheme is to operate the Wells turbine within this range. Maximum power is extracted from the OWC device. This is achieved by regulating the PMSG speed. If the Wells turbine generator speed is controlled at the reference speed, which accurately follows the incident angular speed, the Wells turbine can extract maximum power at multiple operating speeds.

\subsubsection{Field oriented control strategy}

In this subsection, a well-known FOC control strategy is implemented. It is a closed-loop control scheme where the stator current indirectly controls $T_{e}$. Applying FOC strategy to the PMSG-based ocean energy conversion system offers a performance advantage. The main components of the simulated FOC control strategy are PMSG, power converter, speed and current controllers. The control is performed in the $d-q$ reference frame, while $\omega_{r}^{*}$ is obtained from the MPPT algorithm. PI controllers are implemented for current and speed regulation, while the inner current controller response must be quicker than the outer speed controller. In order to reduce Wells turbine generator control complexity, a constant angle control is accomplished by setting $\delta$ at $90^{\circ}$ while the $d$-axis stator current is kept at zero.

As the stator $q$-axis current is relevant to the torque, it is called the torque producing current [90], while the permanent flux and torque angle are kept constant. Under FOC control, rotor position, DC-link voltage, and stator currents are considered as closed-loop feedback signals, as shown in Fig. 4. $i_{d s}^{*}$ is set at zero while $i_{q s}^{*}$ is generated by the speed PI controller. The $d-q$ axis current regulators then obtain the converter voltage signals. For decoupling current control, $\omega_{e} \lambda_{q s}$ is subtracted while $\omega_{e} \lambda_{d s}$ is added, as shown in Fig. 4. The required converter voltage is fed to the SVPWM scheme to generate the gate switching signals for the converter.

\subsubsection{Adaptive back-stepping robust control design}

In this subsection, an $\mathrm{ABC}$ algorithm is designed for MSC control of the OWC device based ocean energy conversion system.

Adaptive control is capable of providing a systematic method for designing controllers of unpredictable systems [91]. This technique is a fusion of back-stepping control and adaptive laws. It can deliver better 


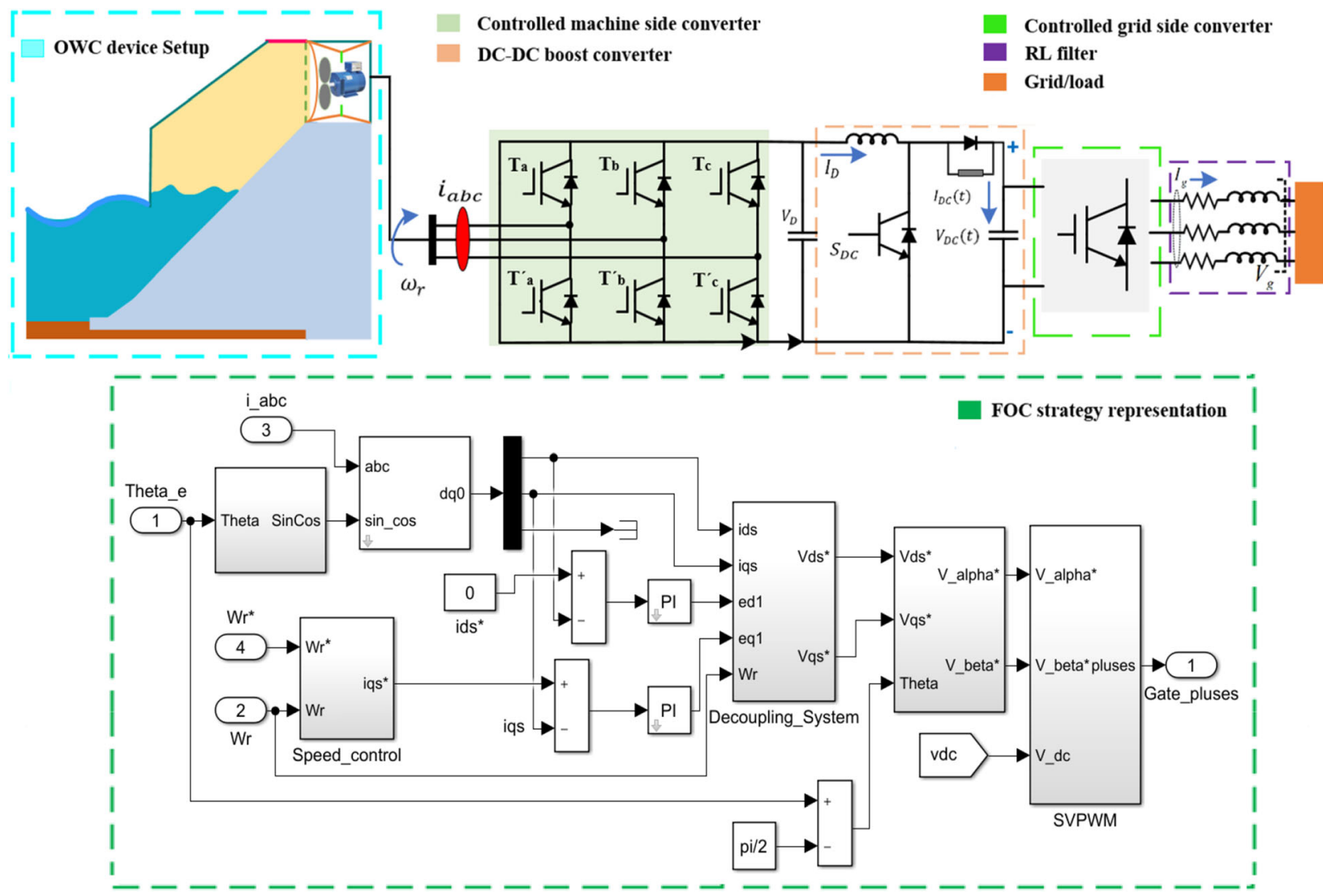

Fig. 4 FOC control strategy in Matlab/Simulink

robustness to the system with known and unknown uncertainties. A non-linear system requires a highly efficient control strategy that can provide robust performance, balanced power, and corresponding stability. For this purpose, Lyapunov functions are calculated and implemented to improve system stability [92].

In the presented ocean energy conversion system, all subsystems contribute by providing a controlled signal for the next subsystem. Positive stable Lyapunov functions are introduced, and guarantee the desired speed tracking with efficient control of the PMSG. The desired speed control is accomplished by controlling $i_{q s}$ while $i_{d s}$ remains at zero. Thus, the $T_{e}$ is proportional to the current, while the stator magnetic flux linkage links to the PMSG rotor magnet linkage flux. Hence, from the relevant equations of PMSG expressed in (7)-(9), there is:

$$
v_{d s}=-\omega_{e} i_{q s} L_{q}
$$

In order to keep the speed tracking error at zero, the components of relevant current are established by considering virtually controlled elements. These are used to drive the speed tracking error and its dynamics to zero in a finite time range. The time derivative of $\omega_{r}$ error and its dynamics are calculated as:

$$
\left\{\begin{array}{c}
\sigma_{\omega}=\omega_{r}^{*}-\omega_{r} \\
\frac{d \sigma_{\omega}}{d t}=\dot{\omega}_{r}^{*}-\dot{\omega}_{r} \\
\dot{\sigma_{\omega}}=\dot{\omega}_{r}^{*}-\dot{\omega}_{r} \\
\dot{\sigma}_{\omega}=-\dot{\omega}_{r} \\
\dot{\sigma}_{\omega}=\frac{1}{J}\left[\begin{array}{c}
1.5 P i_{q s}\left\{\lambda_{p m}+\left(L_{d}-L_{q}\right) i_{d s}\right\} \\
+K_{D} \omega_{r}-T_{t u r b}
\end{array}\right]
\end{array}\right.
$$

Defining the Lyapunov candidate function as:

$$
V_{1}=0.5 \sigma_{\omega}^{2}
$$

the derivate of Lyapunov is obtained as:

$$
\left\{\begin{array}{c}
\dot{V}_{1}=\sigma_{\omega} \dot{\sigma}_{\omega} \\
\dot{V}_{1}=-\sigma_{\omega}^{2} k_{\omega} \\
+\frac{1.5 P \sigma_{\omega} i_{d s} i_{q s}}{J}\left(L_{d}-L_{q}\right) \\
+\frac{\sigma_{\omega}}{J}\left(\begin{array}{c}
1.5 P i_{q s} \lambda_{p m}+\sigma_{\omega} J k_{\omega} \\
+K_{D} \omega_{r}-T_{\text {turb }}
\end{array}\right)
\end{array}\right.
$$

where $k_{\omega}$ represents the angular speed closed-loop feedback constant.

The validity of Lyapunov functions for the stator reference currents are represented as: 


$$
\left\{\begin{array}{l}
i_{d s}^{*}=0 \\
i_{q s}^{*}=\frac{2}{3 P \lambda_{p m}}\left(T_{t u r b}-\sigma_{\omega} J k_{\omega}-K_{D} \omega_{r}\right)=0 \dot{V}_{1}=-k_{\omega} \sigma_{\omega}^{2}<0 \\
\omega_{r}^{*} .
\end{array}\right.
$$

To provide the reference stator voltages based on the adaptive back-stepping calculation, the virtual input stator currents are considered. Therefore, current tracking errors can be expressed as:

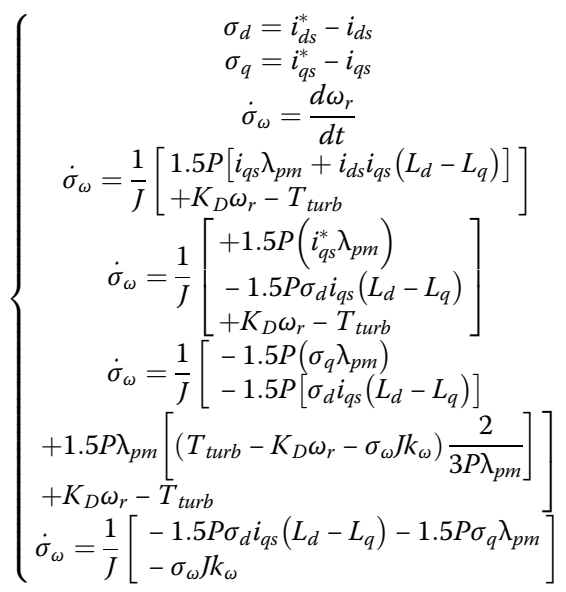

After further solving (16), a new set of equations is obtained as:

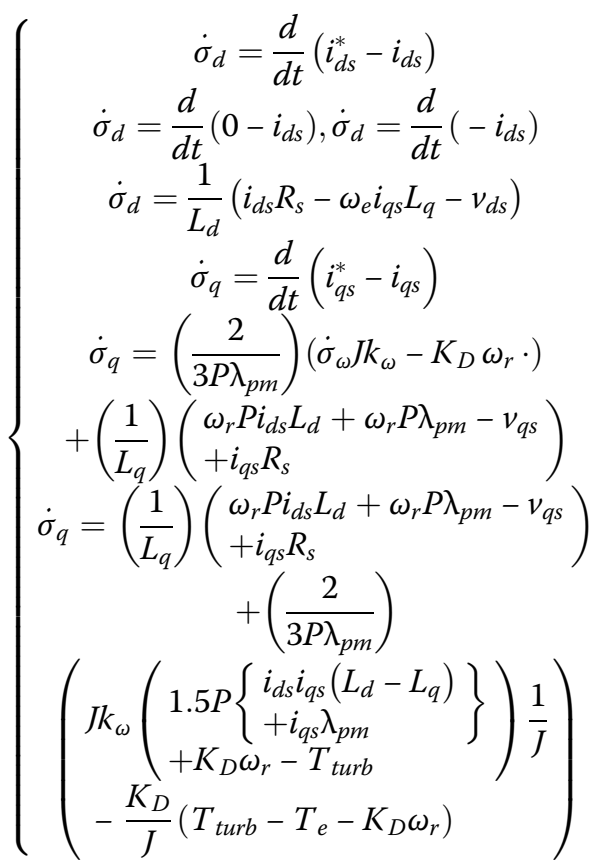

$$
\left\{\begin{array}{c}
\dot{\sigma}_{q}=\left(\frac{2}{3 J P \lambda_{p m}}\right)\left(\left\{\begin{array}{l}
\left.T_{\text {turb }}-1.5 P\left(\begin{array}{l}
i_{d s} i_{q s}\left(L_{d}-L_{q}\right) \\
+i_{q s} \lambda_{p m}
\end{array}\right)\right\} \\
-K_{D} \omega_{r}
\end{array}\right\}\right. \\
\left.+K_{D}\right) \\
\left.+J k_{\omega}\left[\begin{array}{l}
\left.\left.-K_{D} \omega_{r}-1.5 P\left\{\begin{array}{l}
i_{d s} i_{q_{s}}\left(L_{d}-L_{q}\right) \\
+i_{q s} \lambda_{p m}
\end{array}\right\}\right]\right) \\
+T_{\text {turb }}
\end{array}\right]\right) \\
+\frac{1}{L_{d}\left(\omega_{r} P \lambda_{p m}+\omega_{r} P i_{d s} L_{d}-v_{q s}+i_{q s} R_{s}\right)} \\
\dot{\sigma}_{q}=\left[\frac{1}{L_{d}}\left(\omega_{r} P \lambda_{p m}+\omega_{r} P i_{d s} L_{d}-v_{q s}+i_{q s} R_{s}\right)\right. \\
+\left(\left[\frac{\left.2 J k_{\omega}-K_{D}\right)}{3 J P \lambda_{p m}}\right]\right) \\
\left(\left[\begin{array}{l}
-1.5 P\left\{i_{d s} i_{q s}\left(L_{d}-L_{q}\right)+\lambda_{p m} i_{q s}\right\} \\
-K_{D} \omega_{r}+T_{t u r b}
\end{array}\right]\right)
\end{array}\right.
$$

For the evaluation of controlled voltages, a second Lyapunov function is calculated using (16)-(18). Error signals of the rotational speed tracking and stator current components are also considered. The Lyapunov functions can be expressed as:

$$
\left\{\begin{array}{l}
V_{2}=0.5 \sigma_{\omega}^{2}+0.5 \sigma_{d}^{2}+0.5 \sigma_{q}^{2} \\
\dot{V}_{2}=\sigma_{\omega} \dot{\sigma}_{\omega}+\sigma_{d} \dot{\sigma}_{d}+\sigma_{q} \dot{\sigma}_{q}
\end{array}\right.
$$

Substituting the various variables in (19), a new equation is obtained, as shown in (20). The constants $\left(k_{a}, k_{b}\right)$ must contain positive values to ensure the stability of the MSC control system.

$$
\left\{\begin{array}{c}
\dot{V}_{2}=\frac{\sigma_{\omega}}{J}\left[\left\{-1.5 p \sigma_{d} i_{q s}\left(L_{d}-L_{q}\right)\right\}-1.5 p \sigma_{q} \lambda_{p m}\right] \\
+\frac{\sigma_{d}}{L_{d}}\left(i_{d s} R_{s}-\omega_{e} i_{q s} L_{q}-v_{d s}+\sigma_{d} k_{a} L_{d}\right) \\
+\frac{\sigma_{q}}{L_{q}}\left[\left\{\frac{2 L_{q}\left(J k_{\omega}-K_{D}\right)}{3 J p \lambda_{p m}}\right\}\right. \\
\left\{\begin{array}{c}
-1.5 p \lambda_{p m} i_{q s}-K_{D} \omega_{r}-1.5 p i_{d s} i_{q s}\left(L_{d}-L_{q}\right) \\
+T_{t u r b} \\
+\omega_{e} i_{d d} L_{d}+\omega_{e} \lambda_{p m}+i_{q s} R_{s} \\
+\sigma_{q} k_{b} L_{q}-v_{q s} \\
-k_{\omega} \sigma_{\omega}^{2}-k_{a} \sigma_{d}^{2}-k_{b} \sigma_{q}^{2}
\end{array}\right\}
\end{array}\right.
$$

The Lyapunov function derivatives will become negative after inserting the voltage references. Hence, the obtained set of reference equations can be expressed as (21) while the applied adaptive control is shown in Fig. 5.

$$
\left\{\begin{aligned}
v_{d s}^{*}= & {\left[\begin{array}{l}
k_{a} \sigma_{d} L_{d}-\omega_{e} i_{q_{s}} L_{q}+i_{d s} R_{s} \\
-\left\{\frac{1.5 p \sigma_{\omega} i_{q s} L_{d}}{J}\left(L_{d}-L_{q}\right)\right\}
\end{array}\right] } \\
v_{q s}^{*}=\omega_{e} i_{d s} L_{d}+\omega_{e} \lambda_{p m}+i_{q s} R_{s} & +\left[\left\{\frac{2 L_{q}}{3 J p \lambda_{p m}}\left(J k_{\omega}-K_{D}\right)\right\}\right] \\
& {\left[\begin{array}{c}
-K_{D} \omega_{r}- \\
\left.+1.5 p i_{d s} i_{q s}\left(L_{d}-L_{q}\right)\right\}-1.5 p i_{q s} \lambda_{p m} \\
+T_{\text {turb }}
\end{array}\right.} \\
& +k_{b} \sigma_{q} L_{q}-\frac{1.5 \sigma_{\omega} p \lambda_{p m} L_{q}}{J}
\end{aligned}\right.
$$

After further solving (17), it yields $\dot{\sigma}_{q}$ as: 


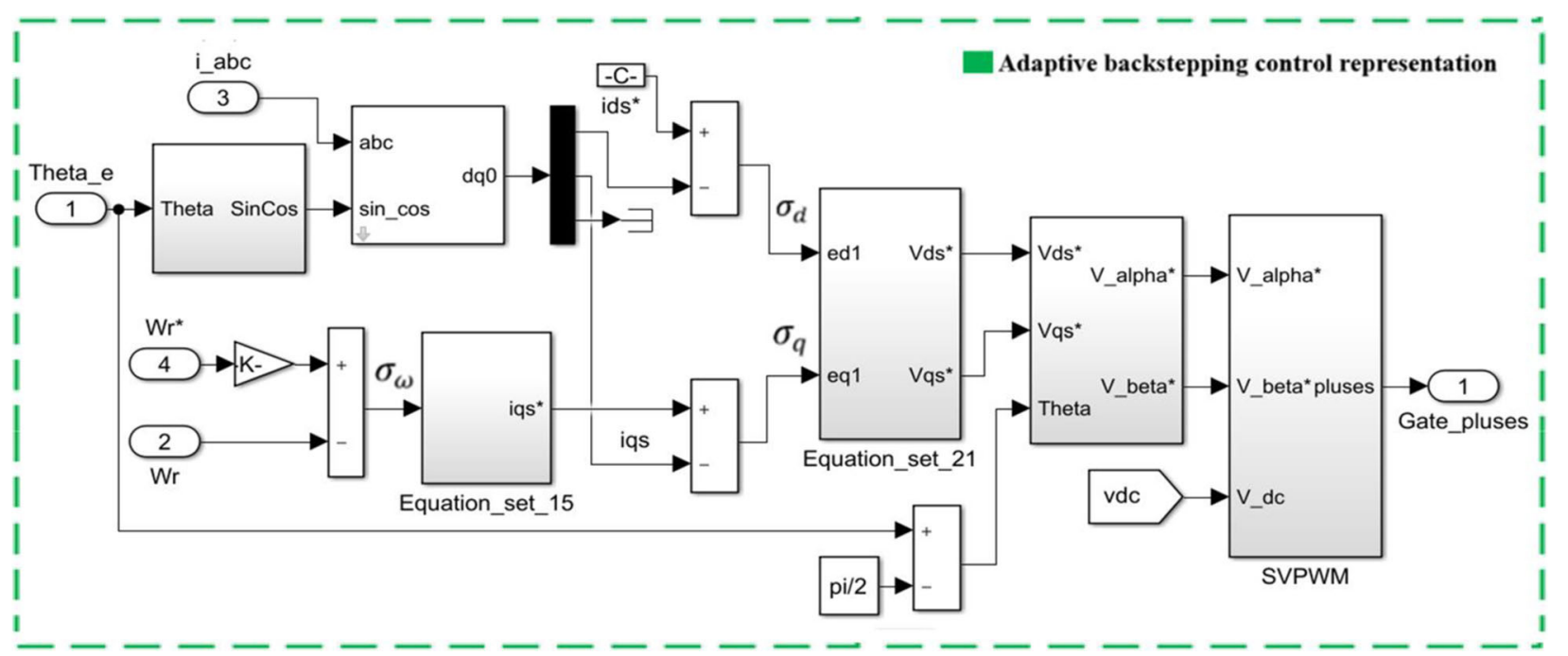

Fig. 5 Adaptive control strategy in Matlab/Simulink

\subsection{Grid side converter control}

The grid side converter (GSC) control strategy, as schematically shown in Fig. 6, is implemented to handle grid synchronization, DC-link voltage, and active and reactive power. The core purpose of this control strategy is to deliver active power generated by the ocean energy conversion system to the grid. The internal loop controls the grid side current while the external loops control the DC-link voltage and reactive power [93]. The DC-link voltage controller generates the reference current for the $d$ axis.

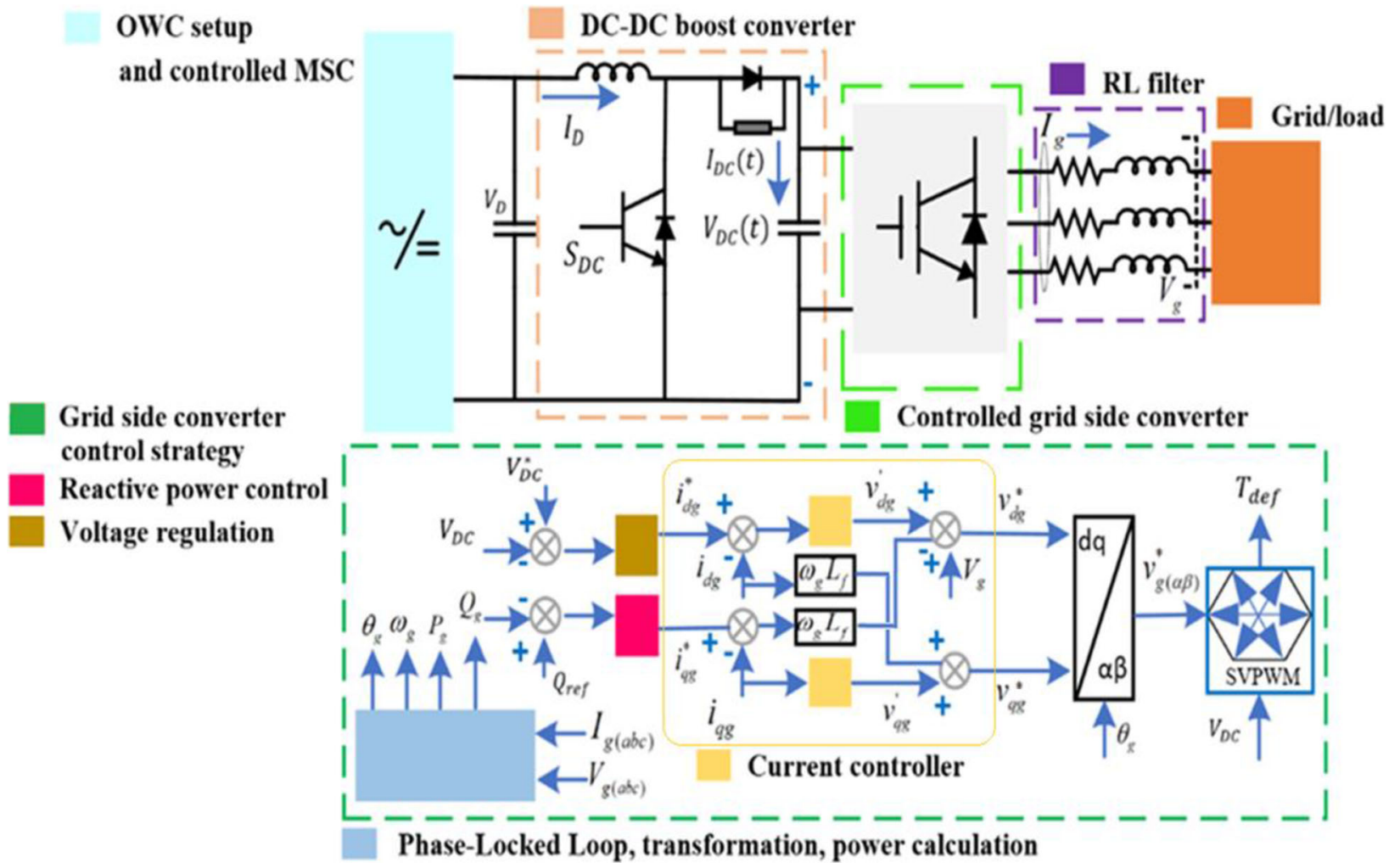

Fig. 6 Schematic of GSC control strategy 
The reference $q$-axis current is kept at zero. The $d-q$ control scheme provides effective control using PI controllers, while active and reactive power control is obtained using the relevant concepts in [94]. The SVPWM scheme is also used for GSC. The relevant set of equations are:

$$
\left\{\begin{array}{c}
v_{d g}=v_{d g}^{\prime}-i_{d g} R_{f}-L_{f} \frac{d i_{d g}}{d t}+i_{q g} \omega_{g} L_{f} \\
v_{q g}=v_{q g}^{\prime}-i_{q g} R_{f}-L_{f} \frac{d i_{q g}}{d t}-i_{d g} \omega_{g} L_{f} \\
i_{d g}^{*}=\frac{P_{r e f} v_{d g}+Q_{r e f} v_{q g}}{v_{d g}^{2}+v_{q g}^{2}} \\
i_{q g}^{*}=\frac{P_{r e f} v_{q g}-Q_{r e f} v_{d g}}{v_{d g}^{2}+v_{q g}^{2}} \\
P_{g}=1.5\left(v_{d g} i_{d g}+v_{q g} i_{q g}\right) \\
Q_{g}=1.5\left(v_{q g} i_{d g}-v_{d g} i_{q g}\right)
\end{array}\right.
$$

where $P_{r e f}$ and $Q_{r e f}$ represent the GSC active and reactive power references, respectively. $R_{f}$ and $L_{f}$ are the filter inductance and resistance, respectively, while $\omega_{g}$ is the grid angular frequency. $V_{D C}^{*}$ can be taken as $V_{\text {rms_ref }} \sqrt{2}$, while active and reactive power at $v_{q g}=0$ and $v_{d g}=|V|$ reference frame are expressed in (23).

\section{Inclusion of energy storage scheme}

A scheme of a DC-DC boost converter connected to a battery bank is installed at the DC-link of the back-to-back power converter of the considered ocean energy conversion system. Battery storage system (BSS) enhances the reliability of the power system [95]. The BSS can either perform as a load or a source [96]. This scheme handles the low power situation caused by potential speed variations. For this reason, the DC-link voltage is kept at a constant level by trading a certain amount of power from the battery.

To keep the DC-link voltage at a constant level, the battery bank can perform charging or discharging according to a switching signal. The initial charging state is taken as $50-55 \%$. The corresponding $V_{D C}$ is compared with the reference $V_{D C}^{*}$ and then the PI controller-based error signal is passed to generate the duty cycle for the insulated-gate bipolar transistor (IGBT) switches. The primary purpose of using a DC-DC boost converter is to raise the input voltage to a constant voltage level. The applied scheme is shown in Fig. 7.

\section{Results and discussions}

In this section, the results of the standalone PMSGbased ocean energy conversion system are examined, while the parameters and operating conditions are shown in the Appendix in Table 4. The waveforms are obtained from the FOC and adaptive control strategies. From (23), the turbine torque coefficient curve values and $C_{a}$ can be estimated as [97]:

$$
\left\{\begin{aligned}
& C_{t}= \frac{\sum_{n=0}^{6} p_{n} \cdot \phi^{n-1}}{\sum_{n=0}^{4} q_{n} \cdot \phi^{n-1}} \\
& C_{a}=4.8 \phi-25 \phi^{3}+18.8 \phi^{2}
\end{aligned}\right.
$$

The generator section is mainly formed by the OWC device, including the Wells turbine, which is coupled with the PMSG. In the modelled OWC device, the flow rate is kept under a level of 120 and is implemented by

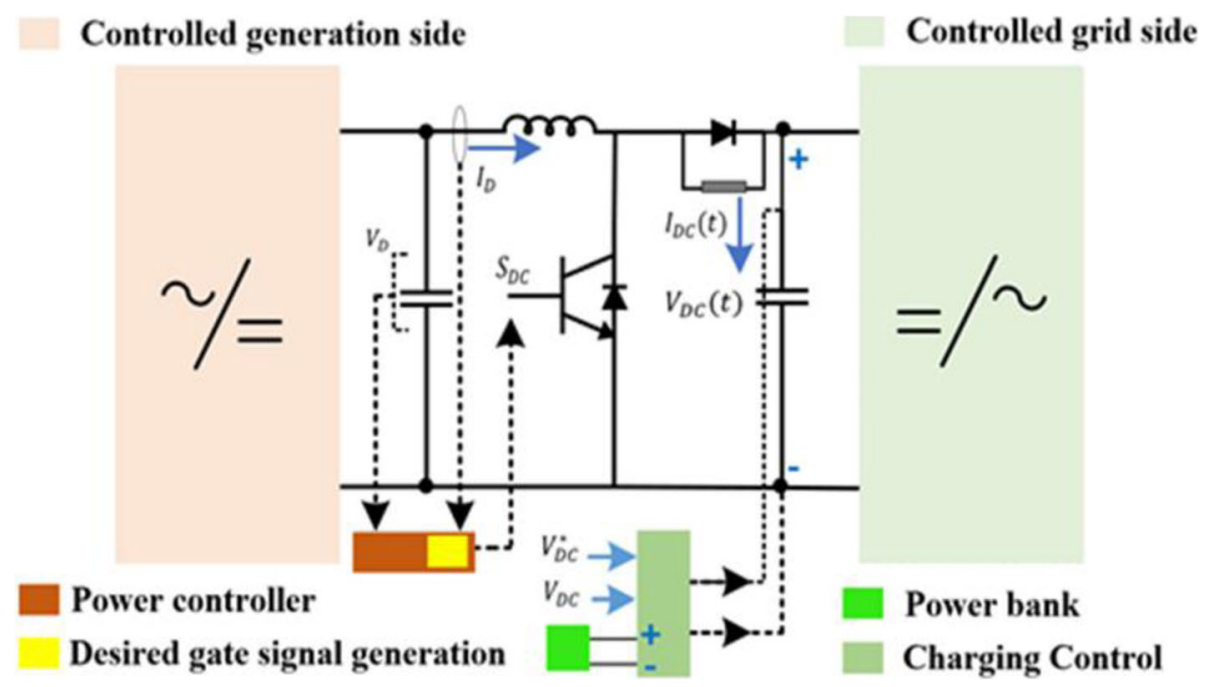

Fig. 7 Scheme of DC-link optimization 


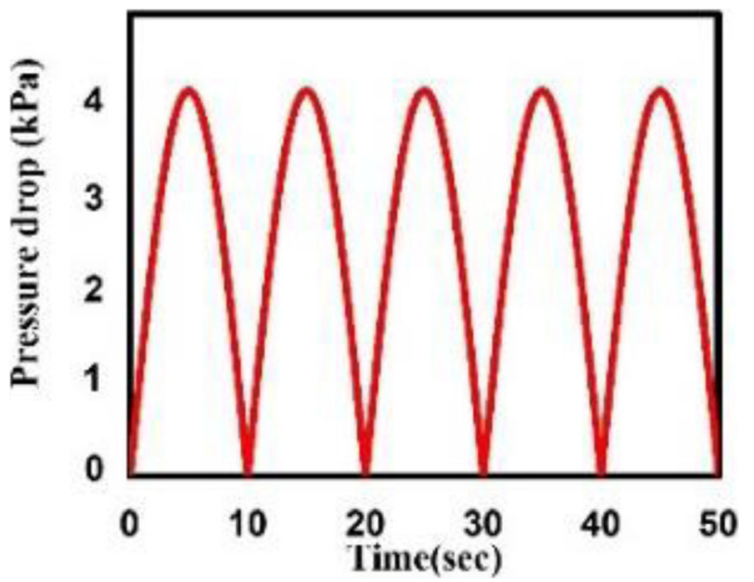

Fig. 8 OWC chamber pressure drop

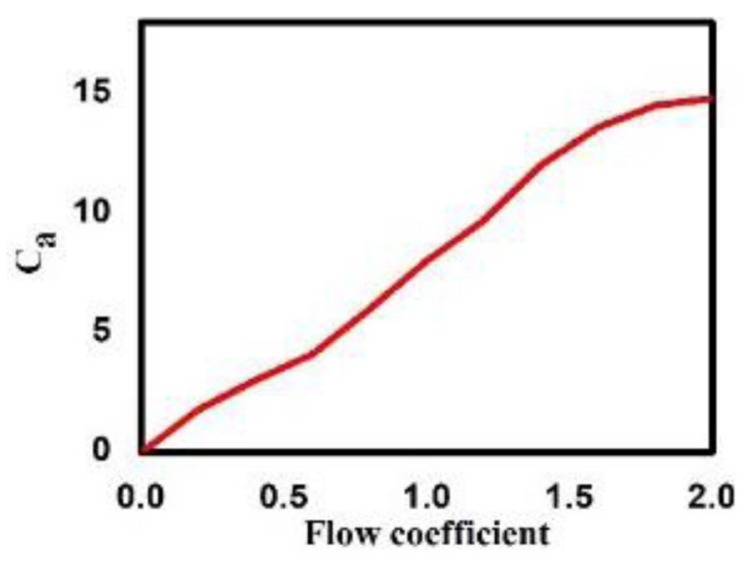

(a)

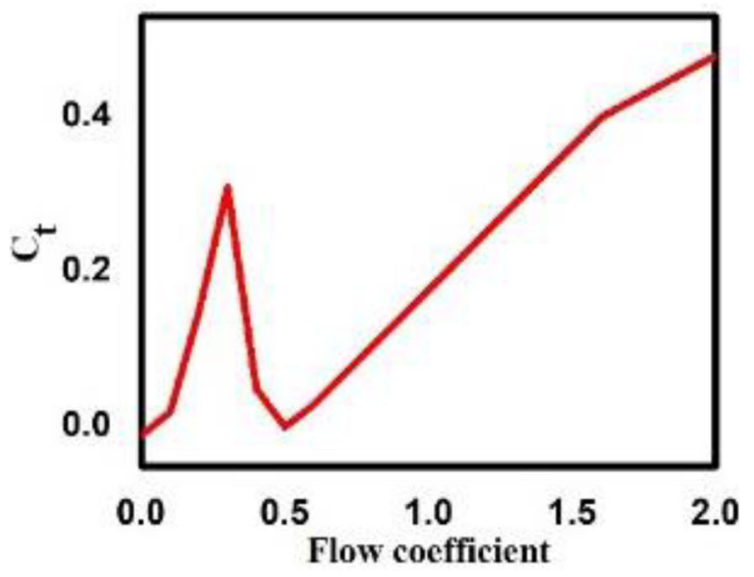

(b)

Fig. 9 Characteristics of Wells turbine. a Power coefficient. $\mathbf{b}$ Torque versus flow coefficient inserting a steady pressure drop of $|4000 \sin (0.314 t)| \mathrm{Pa}$ acting as input as shown in Fig. 8.

When the oscillations are higher than the Wells turbine torque, which is 0.3 in the simulated system, the power produced remains limited to the Wells turbine threshold value. The obtained mechanical power from the incident waves can be increased by keeping the flow coefficient below the required threshold value. The power and torque coefficients for the Wells turbine are shown in Fig. 9(a) and (b), respectively, while the flow coefficient, which helps to generate enough torque from the OWC device setup, is shown in Fig. 10(a). The OWC device can deliver a reasonable flow rate as shown in Fig. 10(b).

Also, the applied FOC control strategy provides the generator $T_{e}$ with a slightly slower response than the adaptive control strategy, as shown in Fig. 11(a) and (b). Rotational speed limits the efficiency of the power

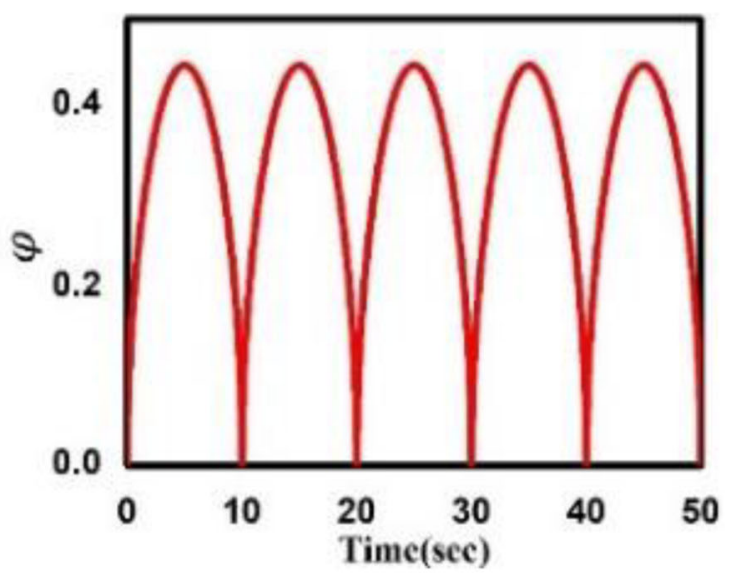

(a)

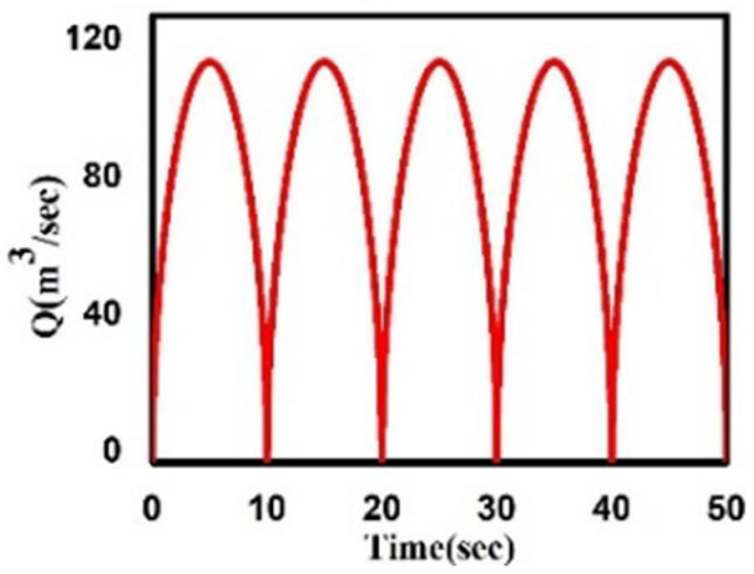

(b)

Fig. 10 Attributes of the modelled OWC chamber. a) Flow coefficient. b) Flow rate 


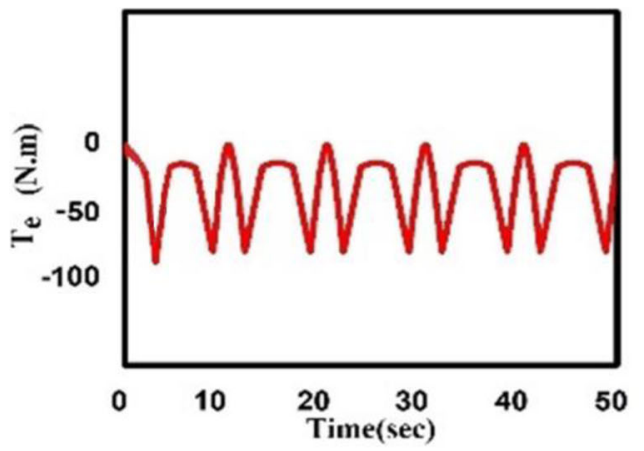

(a)

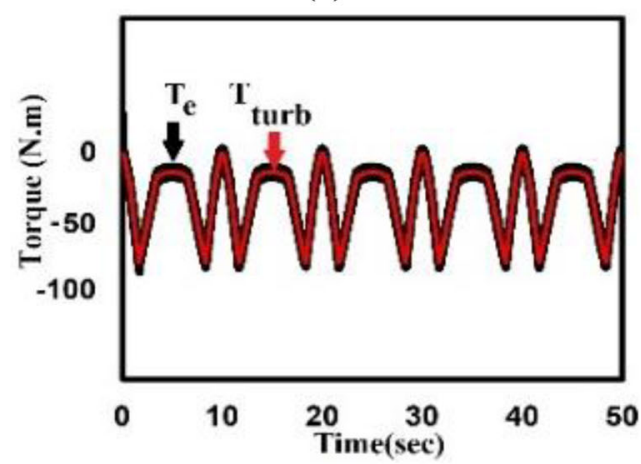

(b)

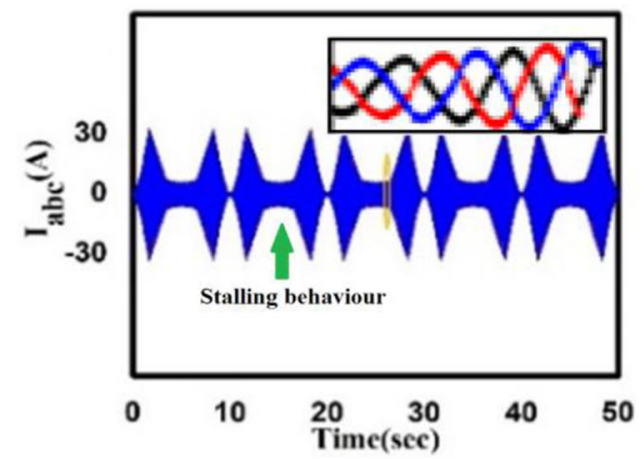

(c)

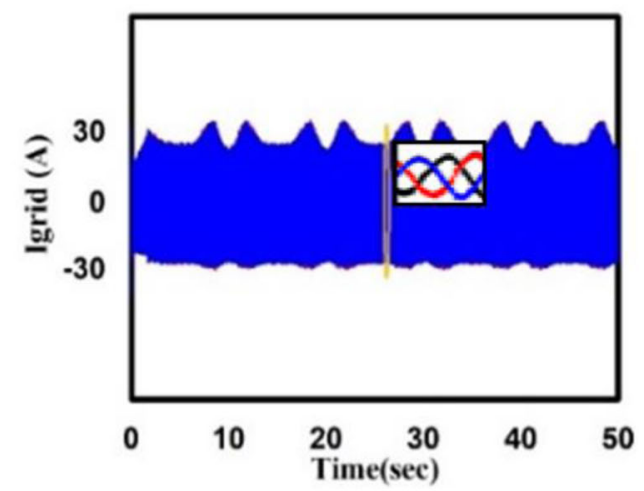

(d)

Fig. 11 Torques and adaptive control-based outputs. a) $T_{e}$ based on FOC strategy. b) $T_{e}$ based on the adaptive control strategy. c) Machine side current output. d) Grid side current output

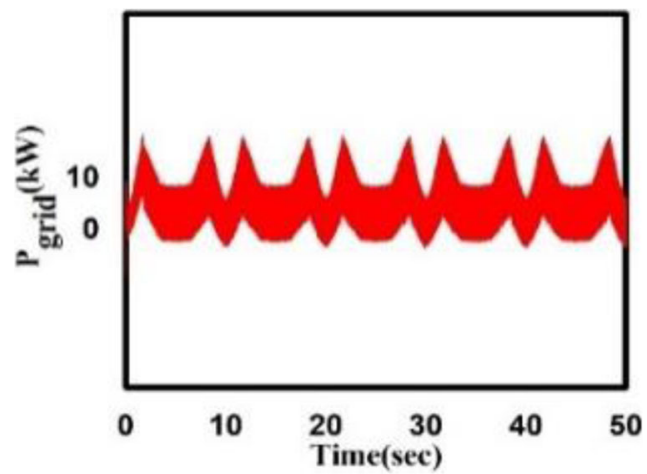

(a)

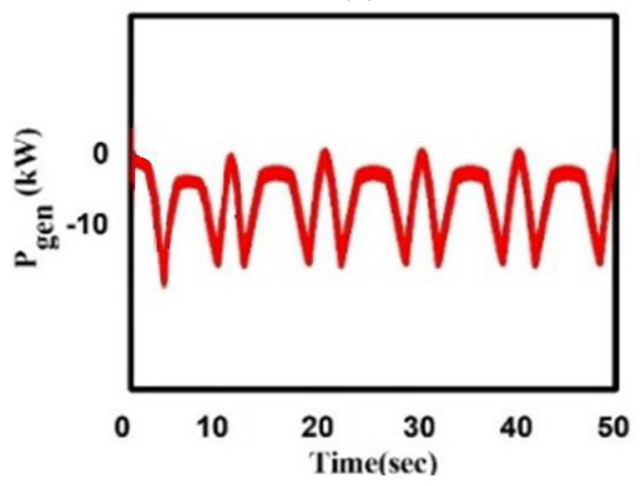

(b)

Fig. 12 Power outputs. a) Adaptive control-based grid side power. b) FOC-based machine side power

generation system because of the Wells turbine stalling behavior, as shown in Fig. 11(c). The proposed electrical control of the PMSG-based wave generation system correctly responds to the entrance pressure drop, which results in a reference speed change under the MPPT strategy. It is responsible for driving the power generation system by providing enough rotational speed from the turbine generator shaft. The

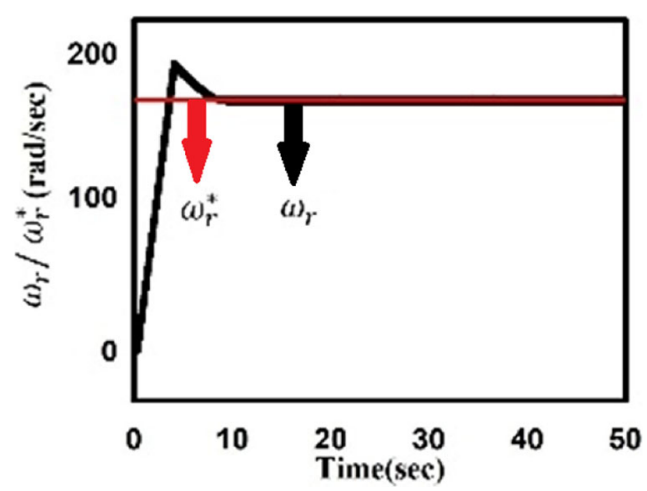

Fig. 13 FOC control-based speed tracking 


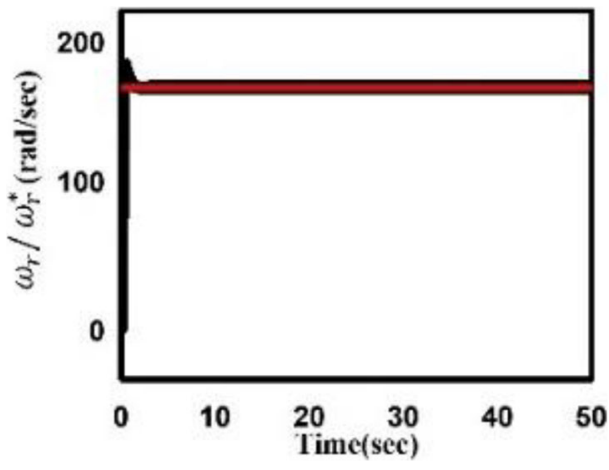

Fig. 14 Adaptive control-based speed tracking

generated machine side current remains within the desired range as shown in Fig. 11(c), while the current delivered to the grid side is shown in Fig. 11(d). The system achieves good quality voltage, electrical current, and power output.

The Wells turbine effectively transfers stable power, as shown in Fig. 12(a) and (b). The actual generator speed under FOC and adaptive control strategy are shown in Figs. 13 and 14. Under the typical wave scenario, both control strategies reasonably follow the

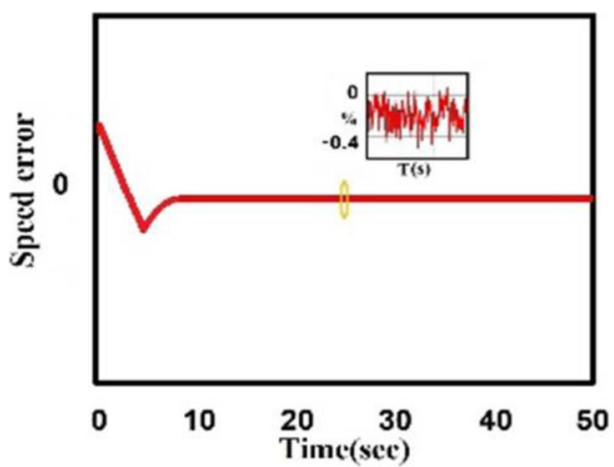

(a)

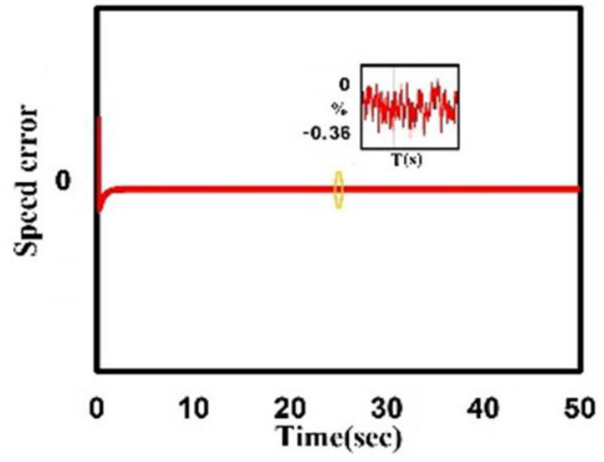

(b)

Fig. 15 Speed tracking error. a FOC-based $\omega_{r} / \omega_{r}^{*}$ error. b Adaptive control-based $\omega_{r} / \omega_{r}^{*}$ error

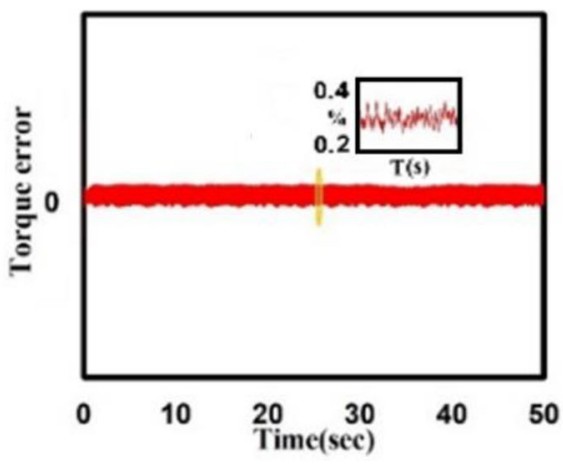

(a)

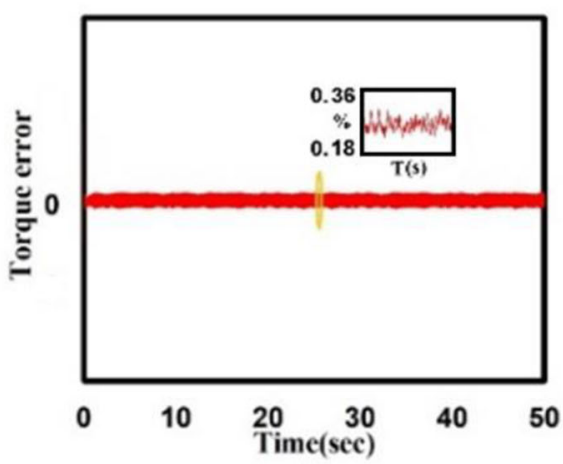

(b)

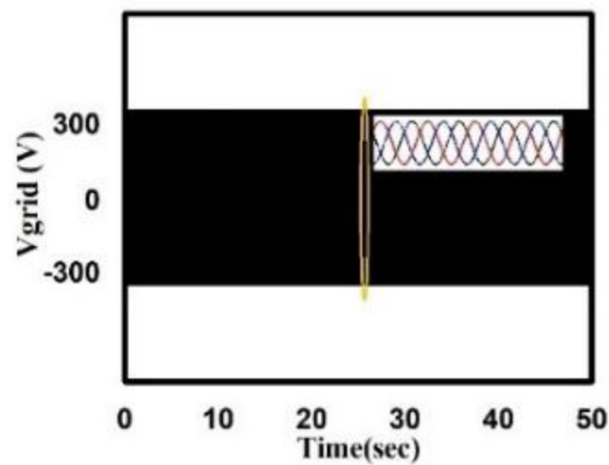

(c)

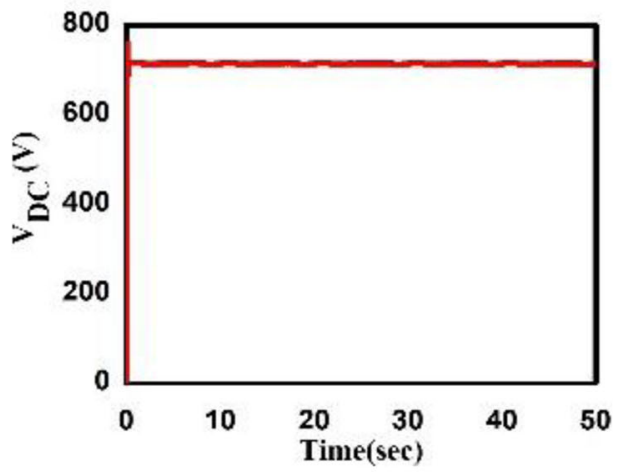

(d)

Fig. 16 Torque error and power system voltages. a FOCbased torque error. $\mathbf{b}$ Adaptive control-based torque error. c Stable grid side voltage. d Optimized DC-link voltage 
Table 3 Critical points of the applied control strategies

\begin{tabular}{lll}
\hline Key features & $\begin{array}{l}\text { FOC control } \\
\text { strategy }\end{array}$ & $\begin{array}{l}\text { Adaptive control } \\
\text { strategy }\end{array}$ \\
\hline Overshoot & High & low \\
Performance & Moderate & high \\
Efficiency & Moderate & high \\
Response time & Low & high \\
Torque error & High & low \\
Speed error & High & low \\
Harmonics & High & low \\
Regulation (parametric) & Low & high
\end{tabular}

speed reference for maximum power output. In the FOC strategy, the system starts full reference speed tracking in $9 \mathrm{~s}$, while under the adaptive control strategy, the system starts tracking the reference speed at around $1.6 \mathrm{~s}$.

It clearly shows the superiority of adaptive control over FOC control strategy for the wave power generation system. Adaptive control of the ocean energy conversion system with minimum delay and less overshoot has been verified, as shown in Figs. 13 and 14.

Adaptive control enhances system stability and robustness by reducing potential errors from the designed control signals as evidenced from Figs. 15 and 16, verifying its improved performance and dominance over FOC control. The speed tracking error is $0.4 \%$ in FOC and $0.36 \%$ in adaptive control as shown in Fig. 15(a) and (b). Similarly, torque and percentage errors for FOC and adaptive control strategies are shown in Fig. 16(a) and (b), respectively.

Figure 16(d) shows the DC-link voltage with the adaptive control under low fluctuations by connecting with an optimized energy storage scheme. The simulation results validate the optimal electrical control for the PMSG-based ocean energy conversion system using the adaptive back-stepping control. The results also support the correct application of the Lyapunov stability technique. It can ensure improved performance under parametric variations and speed changes. The Wells turbine generator operates in high efficiency, while ensuring stable decoupling control. The proposed adaptive control design can offer a better robust response and durable power with lower percentage errors than the traditional FOC. The scope of this research work can be enhanced by introducing more potential uncertainties, e.g., machine stator resistance, irregular wave, and speed conditions. Table 3 summarizes key points of Section 5 .

\section{Conclusions}

The research has shown that the PMSG-based ocean energy conversion system can achieve better performance by implementing a robust adaptive control strategy followed by the Lyapunov method. Highspeed tracking performance is well assured by implementing an optimal solution, which shows the dominance of adaptive control over FOC control. The simulation results verify that the applied non-linear back-stepping control algorithm can deliver high dynamic and steady-state performance with minimum percentage errors for the OWC device-based power generation system. The inclusion of an energy storage system can facilitate the handling of a low power situation. Maximum power is also achieved using the SVPWM technique, generating less harmonic distortion in output voltage and current waveforms, and thus improving the power quality delivered to the electrical grid.

\section{Appendix}

Table 4 The parameters and operating conditions

\begin{tabular}{ll}
\hline PMSG & \\
\hline Power & $18 \mathrm{~kW}$ \\
Pole pairs & 6 \\
Rotor flux linkage & $1.7 \mathrm{~Wb}$ \\
Stator winding resistance & $0.538 \mathrm{Ohm}$ \\
d-axis inductance & $12.98 \mathrm{e}^{-3} \mathrm{H}$ \\
q-axis inductance & $12.98 \mathrm{e}^{-3} \mathrm{H}$ \\
Wells turbine & \\
Pressure drop & $1.5-4.5 \mathrm{kPa}$ \\
Optimal flow coefficient & 0.3 \\
Air density & $1.225 \mathrm{kgm}$ \\
Blade radius & $0.728 \mathrm{~m}$ \\
Cross sectional area & $1.176 \mathrm{~m}^{2}$ \\
Turbine constant & 0.707 \\
Blade chord length & $0.37 \mathrm{~m}$ \\
Blade height & $0.41 \mathrm{~m}$ \\
No. of Blades & 8 \\
DC-link & \\
DC voltage & \\
DC capacitor & $775 \mathrm{~V}$ \\
Phase-to-phase voltage & $2.22 \mathrm{mF}$ \\
\hline & \\
\hline & $380 \mathrm{~V}$ \\
\hline & $50 \mathrm{~Hz}$ \\
\hline
\end{tabular}




\section{Abbreviations}

$P_{i}$ : Incident power; $P_{\text {gen }}$ : Generated power; $I_{a b c}$ : Generated current; $P_{\text {grid }}$ Grid power; I grid: Grid current; $V_{\text {grid: }}$ Grid voltage; $k_{a}, k_{b}, k_{\omega}$ : Control parameters; $i_{d s}, i_{q s}: d-q$ axes of the stator current; $\lambda_{d s,}, \lambda_{q s}: d-q$ axes of the stator flux linkage; $\sigma_{\omega}$ : Speed tracking error; $v_{d s}^{*}, v_{q s}^{*}$ : Reference stator voltages; $i_{d s}^{*}, i_{q s}^{*}: d-q$ axis stator reference currents; $p$ : Laplace operator; $\delta$ : Torque angle; $\omega_{r}^{*}$ : Reference speed; $V_{r m s \_r e f}$ Phase voltage reference; $\varphi_{\text {max }}$ : Maximum flow coefficient; $\dot{\sigma}_{d}, \dot{\sigma}_{q}$ : Derivative of the current tracking errors;

$T$ : Electromagnetic torque

\section{Acknowledgements}

This work is supported by National Natural Science Foundation of China (51477098).

\section{Authors' contributions}

Muhammad Noman performed the study of the algorithm, verified the simulation and draft the manuscript. Guojie Li, Keyou Wang and Bei Han engaged in modifying the paper and submitted it to the PCMP. All authors read and approved the final manuscripts.

\section{Funding}

This work is supported by National Natural Science Foundation of China (51477098).

\section{Availability of data and materials}

Not Applicable.

\section{Competing interests}

No competing interests.

Received: 16 June 2020 Accepted: 29 January 2021

\section{Published online: 02 April 2021}

\section{References}

1. ETIP Ocean (2019). Powering homes today, powering nations tomorrow. Ocean Energy Europe Available: https://www.oceanenergy-europe.eu/wpcontent/uploads/2019/04/ETIP-Ocean-Integrated-Strategy-2019-LR.pdf.

2. Rodrigues, L. (2008). Wave power conversion Systems for Electrical Energy Production. Salamanca: ICREPQ.

3. Drew, B., Plummer, A. R., \& Sahinkaya, M. N. (2009). A review of wave energy converter technology. Proceedings of the Institution of Mechanical Engineers: Part A Journal Power Energy, 223(8), 887-902.

4. ON, E. pelamis Wave Power P2 Demonstration at EMEC. Scottish Power Renewables. (2004). [online]. Available: http://www.emec.org.uk/about-us/wa ve-clients/pelamis-wave-power/.

5. Brown, E. G. Cost of generation User's guide version 3. California State Energy Commission Report. (2016). [online]. Available: https://ww2.energy.ca. gov/2016publications/CEC-200-2016-015/CEC-200-2016-015.pdf.

6. Delay, T. (2009). Building the Future, Today. The Carbon Trust, Report. Available: [online]. https://www.ukgbc.org/sites/default/files/Carbon\%2 0Trust\%20-\%20Building\%20the\%20Future\%20Today.pdf.

7. Shehata, A. S., Xiao, Q., Saqr, K. M., \& Alexander, D. (2016). Wells turbine for wave energy conversion: A review. International Journal of Energy Research, $41,6-38$.

8. De, A., \& F., \& Falcao, O. (2010). Wave energy utilization: A review of the technologies. Renewable and Sustainable Energy Reviews, 14, 899-948.

9. Eidsmoen, H. (1998). Tight-moored amplitude-limited heaving buoy waveenergy converter with phase control. Applied Ocean research, 20(3), 157-161.

10. Amundarain, M.. Alberdi, M., Garrido, A. J. \& Garrido, I. (2010). Control strategies for OWC wave power plants, (pp. 4319-4324). Baltimore: Proceedings of the 2010 American control conference.

11. Bossoufi, B., Karim, M., \& Lagrioui, A. (2014). Matlab and Simulink simulation with FPGA based implementation Adaptative and not Adaptative Backstepping non-linear control of a permanent magnet synchronous machine drive. WSEAS Transaction System Control, 9, 86-100.

12. Rusu, E., \& Onea, F. (2018). A review of the technologies for wave energy extraction. Clean Energy, 2, 10-19.

13. McCormick, M., \& E. (2007). Ocean wave energy conversion. Dover Publications, New York, ISBN-13: 978-0486462455.
14. Garrido, A. J., Garrido, I., Lekube, J., De la Sen, M., \& Carrascal, E. (2016) Modelling of Oscillating Water Column Wave Energy Systems. World Automation Congress (WAC), Rio Grande, 1-6.

15. Penalba, M., \& Ringwood, V. J. (2016). A review of wave-to-wire models for wave energy converters. Energies, 9, 506.

16. Mishra, S. K., Purwar, S., \& Kishor, N. (2016). An optimal and non-linear speed control of oscillating water column wave energy plant with Wells turbine and DFIG. International Journal of Renewable Energy Resource, 6,(3), 95-1006.

17. Lin, H., \& Chao, Q. (2010). Simulation study of modeling and control of direct drive wind turbine under grid fault. Power System Protection and Control, 38(21), 189-195.

18. Dominguez, X., \& Imbaquingo, C. (2015). Vector control for an interior permanent magnet synchronous machine with maximum torque per ampere strategy. Revista Politécnica, 35(1), 1-5.

19. Mahersi, E., Kheder, A., \& Mimouni, M. F. (2013). The wind energy conversion system using PMSG controlled by vector control and SMC strategies. International Journal of Renewable Energy Research, 3, 41-50.

20. Ayadi, M., \& Derbel, N. (2017). Non-linear adaptive Back-stepping control for variable-speed wind energy conversion system-based permanent magnet synchronous generator. International Journal of Advanced Manufacturing Technology, 92, 39-46.

21. Mishra, S., \& K., \& Patel, A. (2017). Wells turbine Modelling and PI control scheme for OWC plant using Xilinx system generator, (pp. 1-6). Allahabad: 2017 4th International Conference on Power, Control \& Embedded Systems (ICPCES).

22. Yan, X., Li, J., \& Wei, X. (2019). Research on control strategy of direct-drive permanent magnet synchronous wind turbine in full wind speed range Power System Protection and Control, 47(23), 138-144.

23. Shang, L., Guo, H., \& Zhu, W. (2020). An improved MPPT control strategy based on incremental conductance algorithm. Protection and Control of Modern Power Systems, 5(14), 1-8.

24. Mahersi, E., \& Kheder, A. (2014). Sensorless control with an adaptive sliding mode flux observer applied to wind PMSG system. Hammamet: 15th International Conference on Sciences and Techniques of Automatic Control and computer Engenering.

25. Amundarain, M. Alberdi, M. Garrido, A J \& Garrido, |. (2011). Neural rotational speed control for wave energy converters. International Journal of Control, 84(2), 293-309.

26. Brahmi, J., Krichen, L., \& Ouali, A. (2009). A comparative study between three Sensorless control strategies for PMSG in wind energy conversion system. Applied Energy, 86(9), 1565-1573.

27. Lekube, J., Garrido, A. J., Garrido, I., Otaola, E., \& Maseda, J. (2018). Flow control in Wells turbines for harnessing maximum wave power. Sensors, 18(2), 535.

28. Garrido, A. J., Garrido, I., Amundarain, M., Alberdi, M., \& De la Sen, M. (2012). Sliding-mode control of wave power generation plants. IEEE Transactions on Industry Applications, 48(6), 2372-2381.

29. Yue, H., Rafael, W., Cecilia, B., Mikael, E., Jens, E., \& Mats, L. (2014). Review on electrical control strategies for wave energy converting systems. Renewable and Sustainable Energy Reviews, 31, 329-342

30. Mishra, S. K., Purwar, S., \& Kishor, N. (2016). Fuzzy logic control of OWC wave energy Plant for Preventing Wells Turbine Stalling, (pp. 1-6). Bikaner: IEEE s Power India International Conference (PIICON).

31. Khemiri, N., Akheder, N., Mimouni, M., \& F. (2012). An adaptive non-linear Back-stepping control of DFIG driven by wind turbine. WSEAS Transactions on Environment and Development, 8(2), 60-71.

32. El-Daoudi, S., Lazrak, L., \& Ait Lafkih, M. (2020). Sliding mode approach applied to Sensorless direct torque control of cage asynchronous motor via multi-leve inverter. Protection and Control of Modern Power Systems, 5(13), 1-10.

33. Aubréea, R., Augera, F., Macé, M., \& Loron, L. (2016). Design of an Efficient Small Wind Energy Conversion System with an adaptive Sensorless MPPT strategy. Renewable Energy, 86, 280-291.

34. Bakhtiari, F., \& Nazarzadeh, J. (2020). Optimal estimation and tracking control for variable-speed wind turbine with PMSG. Journal of Modern Power Systems and Clean Energy, 8, 159-167.

35. Roch, N., Zhu, R., Ping, S., \& Paul, C. (2012). On the efficiency of oscillating water column (OWC) devices in Converting Ocean wave energy to electricity under weakly non-linear waves, (pp. 659-666). Rio de Janeiro: Proceedings of ASME 2012 31st International Conference on Ocean, Offshore and Arctic Engineering, Ocean Space Utilization; Ocean Renewable Energy. 
36. Alberdi, M., Amundarain, M., Garrido, A. J., Garrido, I., \& Maseda, F. J. (2011). Fault-ride-through capability of oscillating water column based wavepower-generation plants equipped with doubly fed induction generator and airflow control. IEEE Transactions on Industrial Electronics, 58, 1501-1517.

37. Setoguchi, T., \& Takao, M. (2006). Current status of self-rectifying air turbines for wave energy conversion. Energy Conversion and Management, 47, 2382 2396.

38. Falcão, A. F., Vieira, L. C., Justino, P. A. P., \& Andre, J. M. C. S. (2003). By-pass air-valve control of an OWC wave power plant. Journal of Offshore Mechanics and Arctic Engineering, 125, 205-210.

39. Takao, M., Setoguchi, T., Kaneko, K., Kim, T. H., Maeda, H., \& Inoue, M. (2002). Impulse turbine for wave power conversion with airflow rectification system. International Journal of Offshore and Polar Engineering, 12(2), ISOPE02-12-2-142

40. Justino, P. A. P., \& Falcão, A. F. (1999). Rotational speed control of an OWC wave power plant. Journal of Offshore Mechanics and Arctic Engineering, 121, 65-70.

41. Gato, L. M. C., Warfield, V., \& Thakker, A. (1996). A performance of a highsolidity Wells turbine for an OWC wave power plant. Jounal of Energy Resource Technology, 118, 263-268.

42. Sarmento, A., Falcão, A., \& F. (1985). Wave generation by an oscillating surface-pressure and its application in wave energy extraction. Journal of Fluid Mechanics, 150, 467-485.

43. M'zoughi, F., Bouallègue, S., Garrido, A. J., Garrido, I., \& Ayadi, M. (2020). Water cycle algorithm-based airflow control for oscillating water column-based wave energy converters. Proceedings of the Institution of Mechanical Engineers, Part I: Journal of Systems and Control Engineering, 234(1), 118-133.

44. Narayanan, V., Murthy, B., Bose, K., Sridhara, S., \& Rao, G. (1996). Dynamic analysis of a grid connected induction generator driven by a wave-energy turbine. In Proceedings of 1996 international conference on drives and energy Systems for Industrial Growth, (p. 4338).

45. Lekube, J., Garrido, A., \& Garrido, I. (2018). Variable speed control in Wells turbine-based oscillating water column devices: Optimum rotational speed. IOP Conference Series: Earth and Environmental Science, 136(1), 012017.

46. Justino, P., A, P., \& Falcão, A. F. (1995). Control simulation of an OWC wave power plant. In Second European Wave Power Conference, (pp. 268-272).

47. Falcão, A. F., De, O., \& Justino, P. A. P. (1995). OWC wave energy converters with valve constrained airflow. 2nd European wave power conference, (pp. 187-194).

48. Sarmento, A., Brito-Melo, A., \& Neumann, F. (2006). Results from sea trials in the OWC European wave energy Plant at Pico, Azores. Florence: Invited Paper for WREC-IX

49. Boake, C. B., Whittaker, T. J., Folley, M., \& Ellen, H. (2002). Overview and initial operational experience of the LIMPET wave energy plant, Proceedings of the 12th international offshore and polar engineering conference (pp. 586-594).

50. Voith Hydro Wave Gen., Ltd., Islay Wave cam, (2013). [online] Available: https://tethys.pnnl.gov/organization/voith-hydro.

51. Heath, T., Whittaker, T. J. T., \& Boake, C. B. (2000). The design, construction and operation of the LIMPET wave energy converter (Islay, Scotland). 4th European Wave Energy Conference, (pp. 49-55).

52. Rashid, H. (2004). Power electronics: Circuits, devices, and applications Pearson/ Prentice Hall.

53. Wilfred, P. J. (2006). Control system for wave energy devices. U.S. Patent, (p. GB2424042) A.

54. Rao, S., R., S., \& Murthy, B. K. (2005). Control of induction generator in a Wells turbine based wave energy system. In International Conference on Power Electronics and Drives Systems (PEDS), 2, (pp. 1590-1594).

55. Munoz-Garcia, A., Lipo, T., \& A., \& Novotny, D., W. (1998). A new induction motor V/F control method capable of high-performance regulation at low speeds. IEEE Transactions on Industry Applications, 34, 813-821.

56. Rezaei, M. M. (2018). A non-linear maximum power point tracking technique for DFIG-based wind energy conversion Systems. Engineering Science and Technology, an International Journal, 21(5), 901-908.

57. Benakcha, M., Benalia, L., Ammar, A., \& Bourek, A. (2018). Wind energy conversion system based on dual stator induction generator controlled by non-linear Back-stepping and PI controllers. International Journal of Systems Assurance Engineering and Management, 10, 1-11.

58. Matraji, I., Al-Durra, A., \& Errouissi, R. (2018). Design and experimental validation of enhanced adaptive second-order SMC for PMSG-based wind energy conversion system. International Journal of Electrical Power \& Energy Systems, 103, 21-30.
59. Ezzat, M., De Leon, J., Gonzalez, N., \& Glumineau, A. (2010). Observercontroller scheme using high order sliding mode techniques for Sensorless speed control of permanent magnet synchronous motor. In $49^{\text {th }}$ IEEE conference on decision and control (CDC), (pp. 4012-4017).

60. Hamida, M. A., De Leon, J., \& Glumineau, A. (2014). High order sliding mode observer and optimum integral Back-stepping control for Sensorless IPMSM drive. International Journal of Control, 87, 2176-2193.

61. Zhang, Z. Z., Zou, J. X., Zheng, G., \& Xu, H. B. (2012). Observer-based Backstepping control of the half-direct permanent magnet wind power generation system. Proceedings of the Institution of Mechanical Engineers, Part l: Journal of Systems and Control Engineering, 226(4), 441-450.

62. Shotorbani, A. M., Mohammadi-Ivatloo, B., Wang, L., Marzband, M., \& Sabahi, M. (2019). Application of finite-time control Lyapunov function in lowpower PMSG wind energy conversion Systems for Sensorless MPPT. International Journal of Electrical Power \& Energy Systems, 106, 169-182.

63. Fantino, R., Solsona, J., \& Busada, C. (2016). Non-linear observer-based control for PMSG wind turbine. Energy, 113, 248-257.

64. Errami, Y., Ouassaid, M., \& Maaroufi, M. (2015). A performance comparison of a non-linear and a linear control for grid connected PMSG wind energy conversion system. International Journal of Electrical Power \& Energy Systems, 68, 180-194.

65. Bossoufi, B., Karim, M., Lagrioui, A., Taoussi, M., \& Derouich, A. (2015) Observer Back-stepping control of DFIG-generators for wind turbines variable-speed: FPGA-based implementation. Renewable Energy, 81, 903-917.

66. Corradini, M. L., Lppoliti, G., \& Orlando, G. (2013). Fully Sensorless robust control of variable-speed wind turbines for efficiency maximization Automatica, 49(10), 3023-3031.

67. Heath, T., \& V. (2012). A review of oscillating water columns. Philosophical Transactions of the Royal Society, 370, 235-245

68. Bailey, H., Ortiz, J. P., Robertson, B., Buckhamn, B. J., \& Nicoll, R. S. (2015). A methodology for wave-to-wire WEC simulations, Proceedings of the 2nd Marine Energy Technology Symposium, Seattle, WA, USA (pp. 15-18).

69. Amundarain, M., Alberdi, M., Garrido, A. J., \& Garrido, I. (2009). Neural control of the Wells turbine-generator module, (pp. 7315-7320). Shanghai: 48th IEEE Conference on Decision and Control (CDC), Chinese Control Conference.

70. Takao, M., \& Setoguchi, T. (2012). Air turbines for wave energy conversion. International Journal of Rotating Machinery, 12, 1-10.

71. O'Sullivan, D. L., \& Lewis, A. W. (2011). Generator selection and comparative performance in offshore oscillating water Column Ocean wave energy converters. IEEE Transactions on Energy Conversion, 26(2), 603-614.

72. Mishra, S. K., Purwar, S., \& Kishor, N. (2018). Maximizing output power in oscillating water column wave power plants: An optimization based MPPT algorithm. Technologies, 6, 15

73. Barambones, O., \& Gonzalez, de Durana, J., \& Calvo, I. (2018). Adaptive sliding mode control for a double fed induction generator used in an oscillating water column system. Energies, 11(11), 2939.

74. Prasad, S., Purwar, S., \& Kishor, N. (2019). Non-linear sliding mode control for frequency regulation with variable-speed wind turbine systems. International Journal of Electrical Power \& Energy Systems, 107, 19-33.

75. Freeman, K., Dai, M., \& Sutton, R. (2014). Control strategies for oscillating water column wave energy converters. Underwater Technology: International Journal of the Society for Underwater, 32(1), 3-13.

76. Garrido, I., Garrido, A., Alberdi, M., Amundarain, M., \& Barambones, O. (2013). Performance of an ocean energy conversion system with DFIG Sensorless control. Mathematical Problems in Engineering, 6, 1-14.

77. Bektache, A., \& Boukhezzar, B. (2018). Non-linear predictive control of a DFIG-based wind turbine for power capture optimization. International Journal of Electrical Power \& Energy Systems, 101, 92-102.

78. Henriques, J. C. C., Gato, L. M. C., Lemos, J. M., Gomes, R., \& Falcao, A. (2016) Peak-power control of a grid-integrated oscillating water column wave energy converter. Energy, 109, 378-390.

79. Amundarain, M., Alberdi, M., Garrido, A., \& J., \& Garrido, I. (2011). Modelling and simulation of wave energy generation plants: Output power control. IEEE Transactions on Industrial Electronics, 58, 105-117.

80. Young, I., \& R. (1999). Wind Generated Ocean waves. Oxford: Elsevier.

81. Brooke, J. (2003). Wave energy conversion. Oxford: Elsevier.

82. Chadwick, A., Morfett, J., \& Borthwick, M. (2004). Hydraulics in civil and environmental engineering. UK: Spon Press.

83. Mzoughi, F., Bouallegue, S., \& Ayadi, M. (2015). Modelling and SIL simulation of an oscillating water column for ocean energy conversion. In International renewable energy congress, (pp. 1-6). 
84. Ruud, K., Frank, K., \& N. (2014). Future energy: Improved, sustainable and clean options for our planet, (pp. 357-382). Amsterdam: Elsevier.

85. Song, S., \& Park, J. (2015). Modelling and control strategy of an oscillating water column-wave energy converter with an impulse turbine module, (pp. 1983-1988). Busan: 15th international conference on control, automation and systems (ICCAS).

86. Akabane, M., Suzuki, H., \& Yamauchi, K. (1984). On the cross-flow turbine for wave power plant. Japan: 1st Symposium on Wave Energy Utilization.

87. Novotny, D., W., \& Lipo, Thomas, A. (1996). Vector Control and Dynamics of AC Drives. Oxford University Press, USA, ISBN 13: 9780198564393.

88. Zhao, Y., Wei, C., Zhang, Z., \& Qiao, W. (2013). A review on position/speed Sensorless control for permanent-magnet synchronous machine based wind energy conversion systems. IEEE Journal of Emerging and Selected Topics in Power Electronics, 1(4), 203-216.

89. Rub, H., A., labal, A., \& Guzinski, J. (2012). High performance control of AC drives with MATLAB/Simulink models, Wiley ISBN: 978-0-470-97829-0.

90. Vas, P. (1998). Sensorless vector and direct torque control. Oxford University Press ISBN: 0-19-856465-1.

91. Trabelsi, R., Khedher, A., Mimouni, M. F., Sahli, F. M., \& Masmoudi, A. (2010). Rotor flux estimation based on non-linear feedback integrator for Backstepping controlled induction motor drives. Electromotion Journal, 17, 163-172.

92. Zhou, J., \& Wang, Y. (2005). Real-time non-linear adaptive Back-stepping speed control for a PM synchronous motor. Control Engineering Practice, 13(10), 1259-1269.

93. Mansour, M., Mansouri, M. N., \& Mmimouni, M. F. (2011). Study and control of a variable-speed wind-energy system connected to the grid. International Journal of Renewable Energy Research, 1(2), 96-104.

94. Rabelo, B., \& Hofmann, W. (2001). Optimal active and reactive power control with the doubly-fed induction generator in the MW-class wind turbines, IEEE 4th International Conference on Power Electronics and Drive Systems, 1 (pp. 53-58).

95. Yilmaz, U., Sezgin, M., \& Go, M. (2020). A model predictive control for microgrids considering battery aging. Journal of Modern Power Systems and Clean Energy, 8, 296-304.

96. Hua, C. C., \& Cheng, C. H. (2010). Design and Implementation of Power Converters for Wind Energy Conversion System, Power Electronics International Conference, Sapporo, Japan, 323-328.

97. Lekube, J., Garrido, A., \& J., \& Garrido, I. (2017). Rotational speed optimization in oscillating water column wave power plants based on maximum power point tracking. IEEE Transactions on Automation Science and Engineering, 14, 681-691.

\section{Submit your manuscript to a SpringerOpen ${ }^{\circ}$ journal and benefit from:}

- Convenient online submission

- Rigorous peer review

- Open access: articles freely available online

- High visibility within the field

- Retaining the copyright to your article

Submit your next manuscript at $\boldsymbol{\nabla}$ springeropen.com 